\title{
SAnCho de Paredes y los Libros De LA CÁMARA DE ISABEL I DE CASTILlA: UNA APROXIMACIÓN
}

\author{
José Julio Martín BARBA ${ }^{1}$ \\ Universidad Eclesiástica San Dámaso. Madrid
}

Recibido: 13 de agosto de 2109

Aceptado: 29 de septiembre de 2019

\begin{abstract}
Resumen
En la Casa de los reyes de Castilla, el oficio de camarero fue considerado uno de los más eminentes. El camarero tenía a su cargo el cuidado, organización y custodia de la cámara real con todas sus pertenencias. En la segunda parte del reinado de Isabel la Católica, este oficio lo desempeñó Sancho de Paredes junto a su esposa Isabel Cuello. Ambos realizaron con esmero su trabajo, como comprobamos en los libros de la cámara, su instrumento de trabajo. A la muerte de la reina, después de entregar todos los objetos que tenían a su cargo, recibieron de Juana I, la sucesora en el trono, la carta de finiquito.
\end{abstract}

\section{Palabras clave}

Sancho de Paredes, Isabel Cuello, cámara de la reina, camarero, libros de la cámara.

\begin{abstract}
Among the Household of the Castilian Kings, the trade of chamberlain was one of the most noted. The chamberlain was in charge of the care, organization and custody of the royal chamber and its belongings. During the reign of Isabel I of Castile, the chamberlain was Sancho de Paredes along with his wife Isabel Cuello. They both put a lot of effort into the job they were performing, as it can be appreciated in the chamber books, which were their work tool. With the death of the Catholic queen, after returning all the objects they were in charge of, the successor of the throne, the queen Juana, gave them the settlement.
\end{abstract}

\section{Keywords}

Sancho de Paredes, Isabel Cuello, queen's chamber, chamberlain, chamber books.

\section{Sommario}

Tra la corte della Corona di Castiglia, il titolo di ciambellano era considerato uno dei più eminenti. Il ciambellano era incaricato della cura, dell'organizzazione e della custodia della camera reale con tutte le sue cose. Nella seconda parte del regno di Isabella I di Castiglia, il ciambellano era Sancho de Paredes insieme a sua moglie Isabel Cuello. Entrambi hanno svolto il loro lavoro con cura, come abbiamo verificato nei libri della camera, il suo strumento di lavoro. Alla morte della

\footnotetext{
1 Universidad Eclesiástica San Dámaso. Correo electrónico: jotesco@gmail.com. OrCID: https://orcid. org/0000-0001-8916-7357.
} 
Regina Cattolica, dopo aver restituito tutti gli oggetti di cui erano a capo, il successore del trono, la regina Juana, diede loro la lettera di accordo.

\section{Parole chiave}

Sancho de Paredes, Isabel Cuello, camera della Regina, ciambellano, libri da camera.

\section{Introducción ${ }^{2}$}

Poco después de la muerte de Isabel la Católica, sus camareros Sancho de Paredes e Isabel Cuello se apartaron de la Corte y se retiraron a Cáceres. Consigo se llevaron los libros de la cámara, pasando a formar parte de su archivo familiar. Sus sucesores, de una generación a la siguiente, se fueron legando estos libros con el resto del patrimonio hasta el día de hoy, que los encontramos integrados en el fondo documental de la Fundación Tatiana Pérez de Guzmán el Bueno y conservados en perfecto estado en el archivo del palacio cacereño de los Golfines de Abajo.

Aunque han sido varios los historiadores que quisieron consultar estos libros, pocos han sido los que accedieron a ellos. El primero que los consultó y mencionó en una publicación fue Miguel Ángel Ortí Belmonte en 1954, que hizo una brevísima descripción de ellos en un artículo, en el que reconoció con toda franqueza que su estudio estaba "incompleto, pues falta el estudio detallado de los Libros de Cámara de la Reina" y que no se encontró con salud ni con medios económicos "para transcribir y publicar más de tres mil folios, que es la documentación encontrada". Aunque comunicó la existencia de estos libros al Consejo Superior de Investigaciones Científicas y al historiador Antonio de la Torre y del Cerro, "vicisitudes ajenas a la voluntad de este señor y del Consejo han dado lugar que hasta ahora no se haya hecho nada que trajera como consecuencia que este hallazgo, fruto de mi trabajo, sea aprovechado por otros"3. Antonio de la Torre ciertamente accedió a ellos y, de hecho, transcribió el contenido del Libro Manual en su obra Testamentaría de Isabel la Católica, pero omitió la fuente de donde lo había obtenido 4 . Tarsicio de Azcona lo intentó, pero

\footnotetext{
2 Agradezco enormemente tanto a la Fundación Tatiana Pérez de Guzmán el Bueno, que me permitió consultar aquellos fondos estando aún en fase de ordenación, catalogación y digitalización, como a Miguel Ángel Arroyo, el director del palacio de los Golfines de Abajo, que me han proporcionado todas las facilidades para poder realizar este estudio. Asimismo, agradezco al personal del Archivo General de Simancas y del Archivo Histórico Nacional todo su trabajo y disponibilidad. Igualmente mi reconocimiento al equipo editorial de esta revista Medievalismo, porque gracias a su esfuerzo y dedicación hoy ve la luz esta investigación.

Abreviaturas: AGS $=$ Archivo General de Simancas, $\mathrm{CCA}=$ Cámara de Castilla, $\mathrm{CMC}=$ Contaduría Mayor de Cuentas, $1 \mathrm{EP}=1^{\mathrm{a}}$ Época, $\mathrm{CSR}=$ Casa y Sitios Reales, $\mathrm{LEG}=$ legajo, PTR $=$ Patronato Real, RGS $=$ Registro General del Sello. EMR,MER= Escribanía Mayor de Rentas, Mercedes. AHN = Archivo Histórico Nacional. TPGB = Archivo Histórico de la Fundación Tatiana Pérez de Guzmán el Bueno.

3 Ortí Belmonte, "Cáceres bajo la Reina Católica y su camarero Sancho Paredes Golfin", pp. 94 y 264266.

4 De la Torre y del Cerro, Testamentaría de Isabel la Católica, pp. 273-277.
} 
concluyó diciendo que "a pesar de nuestro empeño, no tuvimos acceso a dichos libros originales"s. Del mismo modo Álvaro Fernández de Córdova dio a entender que tampoco pudo consultarlos porque "en la actualidad pertenecen a una casa nobiliaria". Cuando hace unos años buscaba el porqué un códice del siglo X, creado en el monasterio de Valeránica por Florencio, uno de los mejores calígrafos hispanos, había llegado a parar a la catedral de Córdoba, descubrí con gran sorpresa que este libro había pertenecido a Isabel la Católica, y, queriendo saber seguidamente cómo había llegado a parar a sus manos, sin ignorar que dicha información solo la hallaría en los libros del camarero, di con la mencionada Fundación que los custodia con esmero?

Fruto de este acercamiento a los libros de Sancho de Paredes e Isabel Cuello presento este escueto trabajo. Ojalá en el futuro vean la luz nuevos estudios sobre esta documentación interesantísima, que ciertamente lo merece.

\section{La cámara de la reina y sus camareros}

En los últimos años los profesores Domínguez Casas ${ }^{8}$, Fernández de Córdova ${ }^{9}$ y González Marrero $^{10}$ han publicado interesantes estudios sobre la cámara de la reina Isabel. Igualmente han visto la luz recientes estudios sobre la cámara de los reyes y reinas precedentes en la Corona de Castilla de la mano de los profesores Ladero Quesada $^{11}$, Cañas Gálvez ${ }^{12}$ y Pelaz Flores ${ }^{13}$.

\footnotetext{
5 Azcona, Isabel la Católica. Estudio crítico de su vida y reinado, p. 949 n. 110: "Queremos aludir a un importante problema crítico sobre esta documentación: en la cámara de la reina existían Libros de inventario, a cargo del camarero Sancho de Paredes. En ellos se anotaban las entradas y salidas, las adquisiciones y los regalos, con su descripción y su valor. De seguro que en Toro los testamentarios trabajaron sobre dichos libros; aunque esto no les libró de escribir su propio inventario con los bienes que iban llegando a sus manos y con los existentes en dichos libros. Ahora bien, los libros de Sancho de Paredes, originales de la Cámara, no quedaron en la corte, ni más tarde pasaron al archivo de Simancas; quedaron en el archivo particular de Paredes y con posterioridad en el archivo familiar en Cáceres; en la actualidad pertenecen a una casa nobiliaria".

6 Fernández de Córdova Miralles, La Corte de Isabel I. Ritos y ceremonias de una reina (1474-1504), p. 160 .

7 Cf. Martín Barba, "Identificación de un libro propiedad de Isabel la Católica: el Smaragdo de la catedral de Córdoba"; - , "La fortuna del Smaragdo de Córdoba desde su creación hasta la almoneda de los bienes de Isabel I de Castilla".

8 Domínguez Casas, Arte y etiqueta de los Reyes Católicos. Artistas, residencias, jardines y bosques, pp. 201-236; - “Las Casas de las reinas hispano-portuguesas de Juan II a los Reyes Católicos"; —-División de espacios hombres-mujeres en la Corte de los Reyes Católicos".

9 Fernández de Córdova Miralles, La Corte de Isabel I. Ritos y ceremonias de una reina (1474-1504); - "Sociedad cortesana y entorno regio".

10 González Marrero, La casa de Isabel la Católica. Espacios domésticos y vida cotidiana; - "Las mujeres de la Casa de Isabel la Católica".

11 Ladero Quesada, "La Casa Real en la Baja Edad Media".

12 CAÑas Gálvez, "Las casas de Isabel y Juana de Portugal, reinas de Castilla. Organización, dinámica institucional y prosopografía (1447-1496)"; — "La cámara de Juan II: vida privada, ceremonia y lujo en la corte de Castilla a mediados del siglo XV".

13 Pelaz Flores, La Casa de la Reina en la Corona de Castilla (1418-1496).
} 
En la Edad Media "cámara" se entendía como el espacio doméstico donde la persona regia desarrollaba su vida privada cotidiana, donde se vestía, dormía, comía y tenía una cierta intimidad; no era una única dependencia, sino varias las que constituían la cámara, con una gradualidad espacial de intimidad o privacidad. El término "cámara" también hacía referencia a la alcoba o lugar donde se duerme (que no siempre fue el lugar más íntimo, si atendemos a lo narrado por Diego de Valera el día en que se casaron los jóvenes príncipes Isabel y Fernando ${ }^{14}$ ). Dentro de las diversas estancias palaciegas que formaban la cámara estaba el "retrete", lugar de mayor privacidad, donde se guardaban los objetos más íntimos y personales, y donde la familia real podía comer u orar a Dios. Mientras que las llaves de la cámara estaban a cargo de un mozo de la cámara, de las del retrete se encargaba otro mozo, elegido de entre los más antiguos y fieles servidores.

Por el carácter itinerante de la corte castellana bajomedieval, los aposentos regios de las distintas residencias y palacios eran ornados para la habitabilidad de los reyes solo cuando se alojaban en ellos. Se utilizaban gran profusión de paños y objetos lujosos como alfombras, cojines, vajillas, doseles, tapices, vasos sagrados para las ceremonias cortesanas, etc., y cuando la corte marchaba con los monarcas a otro lugar, lo desmontaban todo para de nuevo montarlo en el destino siguiente. Esta vida les obligó a desplazarse constantemente con todas las cosas de la cámara y disponerlas convenientemente en los diferentes lugares donde se hospedaban, ya fueran castillos, palacios urbanos o nobiliarios, monasterios reales o campamentos provisionales durante la contienda contra los musulmanes: tapices, muebles, ajuar, menaje, libros, objetos sagrados, joyas, vestidos, incluso mascotas constituían la llamada "recámara", es decir, todos los objetos personales que los reyes llevaban consigo en arcas o baúles.

En la corona de Castilla el oficio de camarero mayor fue vitalicio y hereditario, y recayó desde antiguo en los Fernández de Velasco, vinculados al título de condestables de Castilla. Comenzaron en 1370, cuando el rey Enrique II nombró camarero regio a Pedro Fernández de Velasco I (1370-1384); le sucedió, tras su muerte, Juan de Velasco (1384-1418), y sucesivamente Pedro Fernández de Velasco II (1418-1470), Pedro Fernández de Velasco III (1470-1492) y Bernardino Fernández de Velasco (14921512). Este último es el que desempeñó el oficio durante los últimos doce años de la vida de la reina. Recibió por ello 67.600 maravedís anuales ${ }^{15}$, y gozó además de los títulos de I duque de Frías y II conde de Haro. En el caso de la reina Isabel, además del camarero mayor, tenía su camarera mayor. Primero fue Clara de Alvarnáez, esposa de su mayordomo mayor Gonzalo Chacón, y cuando esta murió en 1497, la suplió

\footnotetext{
14 "Todo se consumió en fiestas y danças e mucha alegría; e la noche venida, el prínçipe e la prinçesa consumieron el matrimonio. Y estavan a la puerta de la cámara çiertos testigos puestos delante, los quales sacaron la sábana que en tales casos se suele mostrar, demás de aver visto la cámara do se ençerraron; la qual en sacándola, tocaron todas las tronpetas y atabales y menistriles altos, y la amostraron a todos los que en la sala estavan esperándola, que estava llena de gente...". Memorial de diversas hazañas: crónica de Enrique IV, ordenada por Mosén Diego de Valera, p. 169.

15 Solana Villamor, "Cargos de la Casa y Corte de los Reyes Católicos”, pp. 33-34.
} 
su nuera Inés Manrique. Ahora bien, hemos de entender que camarero mayor era un título honorífico y que, como tal, ejercía sus funciones en momentos muy especiales, siendo el teniente de camarero quien realizaba el trabajo cotidiano.

El camarero tenía a su cargo el cuidado, organización y custodia de la cámara real con todas sus pertenencias. Ya decía Alfonso X en las Partidas que

deue guardar la cámara, do el rey aluergare, e su lecho, e los paños de su cuerpo, e las arca, e los escritos del rey: e maguer sepa leer, no los deue leer ni dexar a otro que los lea, e sobre todas las cosas ha menester que non sea mesturero ni descobridor de lo que viere e oyere, mas deue ser cuerdo et callado, e de buena poridad. E quando tales fuessen el repostero e el camarero, deueles rey fazer bien e merced ${ }^{16}$.

De modo que no solo debía custodiar las cosas del monarca, sus joyas y sus escritos, sino también ser prudente y celoso de su oficio, sensato, discreto y nada chismoso, cualidades todas muy necesarias para desarrollar su actividad en los ámbitos más íntimos. Si estas virtudes brillaban en él, sin duda sería recompensado en vida con diversas honras y beneficios. Por ello, Gonzalo Fernández de Oviedo, que había ejercido de mozo de la cámara del príncipe Juan en su juventud y luego mozo de cámara de las llaves, y conocía por dentro muy bien el funcionamiento de la Cámara y de sus oficiales, escribió en el Libro de la cámara real del príncipe don Juan que este oficio era necesario que recayera "en persona de buena sangre, generoso, e naturalmente noble e aprovado en virtudes; porque, como es dicho, es más ordinariamente visto ante el prínçipe e siempre el tal es su secreto consejero". La continua cercanía física al príncipe daba al camarero mucho prestigio y los beneficios que obtenía de su cargo hacían que se considerase "grande e de los mejores e de los más preeminentes ofiçios de la Casa Real el del camarero, así en onor como en provechos; tanto que es opinión de muchos que es el mejor ofiçio de la Casa Real, porque es más continuo e conversable çerca de la persona del prínçipe"17.

En manos de un nutrido número de oficiales con diversos cometidos estaba la atención a los soberanos en sus asuntos privados como comer, rezar, descansar o vestir, así como cuidar de los aposentos regios donde estas actividades se realizaban ${ }^{18}$-mozos de la cámara, escribanos de la cámara y de las joyas, adobador de los doseles, de la música y de la tapicería, dueñas y damas de la Casa, comprador de las cosas de cámara, continos...-y al frente de este amplio grupo de servidores se encontraba el camarero.

\footnotetext{
16 Segunda Partida, título IX, ley XII. p. 25.

17 Fernández de Oviedo y Valdés, Libro de la Cámara Real del príncipe don Juan, pp. 87-88.

18 En el Libro de asientos de los gastos de la reina doña Isabel aparece la relación de todos los oficiales que estuvieron al servicio de la reina a partir de 1497 y que formaban su Casa. Están agrupados en tres secciones: los miembros de la capilla, los oficiales de cámara y los pajes. Véase la obra pionera DE LA Torre y del Cerro, La casa de Isabel la Católica.
} 


\section{Sancho de Paredes e Isabel Cuello, camareros}

Los esposos Martín Cuello y Beatriz de la Peña ejercieron de tenientes de camarero mayor desde "el tiempo de la princesa"19. Martín fue comendador santiaguista de Segura y aparece en el Libro de asientos de los gastos de la reina doña Isabel con un salario de 12.000 maravedís, que en 1481 se le acrecentó en 30.000 y percibió anualmente hasta 1500, año en el que muy posiblemente murió. A su esposa Beatriz de la Peña, conocida como Beatriz Cuello al tomar el apellido de su marido al casarse ${ }^{20}$, se le libraban 12.000 maravedís y 4.000 a cada una de las hijas que la ayudaban ${ }^{21}$; dijo de ella Gonzalo Fernández de Oviedo en Batallas y Quinquagenas que "era la camarera, así en la tapiçería e plata e cámara prinçipal, como en ese título de camarera"’22. En ese mismo año de 1500, el 30 de septiembre concretamente, Beatriz Cuello hizo testamento y poco después debió morir también ${ }^{23}$.

Isabel Cuello, hija de ambos, casó en 1484 con el contino Sancho de Paredes y ambos recibieron de parte de la reina "para su dote y casamiento" el portazgo de la ciudad de Cáceres como juro de heredad, regalo verdaderamente magnífico por los ingresos continuos que de él recibirían, aunque les costó comenzar a cobrarlo ${ }^{24}$. Este joven era hijo de Alonso Golfín y Mencía de Tapia y de ellos recibió el nombre de su abuelo materno, como narra él mismo en la crónica que redactó sobre su familia, los Golfines:

Del dicho Alonso Golfín mi padre y de la dicha Mençía de Tapia mi madre, no quedó otro hijo ni hija ni lo ovieron sino yo, que me llamó mi padre Sancho de Paredes como a mi abuelo, por que le prometió de mí hazer mayorazgo de su hazienda, y pensando que no avría más hijos y así yo quedé con el dicho nombre, y por desacuerdo que ovo entre ellos, syn el mayorazgo ${ }^{25}$.

Sus ascendientes paternos y maternos pertenecían a la nobleza urbana de la villa de Cáceres, los señores de Torre Arias, y, gracias a ello, accedió a la corte como contino

\footnotetext{
19 AGS,CSR,LEG,43-212, fol. 92.

20 González Marrero dice que su nombre de soltera sería Beatriz Gómez; Fernández de Córdova dice que era María Cortés. Ortí Belmonte dice que su apellido de soltera era de la Peña, que renunció por el de su marido al casarse. Cf. Gonzélez Marrero, "Las mujeres de la Casa de Isabel la Católica”, p. 853; Fernández de Córdova, La Corte de Isabel, p. 146, n. 599; Ortí Belmonte, "Cáceres bajo la Reina Católica y su camarero Sancho Paredes Golfin", p. 260.

21 AGS,CSR,LEG,104, fol. 276.

22 Fernández de Oviedo, Batallas y quinquagenas II, p. 205.

23 Ortí Belmonte, "Cáceres bajo la Reina Católica y su camarero Sancho Paredes Golfin”, p. 267.

24 TPGB, CA. 53/003. Este impuesto parece que no les fue fácil cobrarlo: AGS, RGS, LEG, 1448807,249; 1448807,$253 ; 1448807,254 ; 148903,213$.

25 TPGB, CA. 61/001, fol. 5.
} 
de la casa de la reina en 1483, con un salario de 30.000 maravedís ${ }^{26}$. Los continos, en torno al centenar en la Casa Real de Isabel, procedían de las familias de regidores de las distintas ciudades del reino. Ser contino era un modo de promoción social de los miembros de las élites urbanas por el cual accedían al círculo cortesano y ejercían un servicio de confianza, "a medio camino entre las antiguas situaciones de colaborador personal del rey, criado en su Corte, y las nuevas propias de un auténtico cuerpo de funcionarios" ${ }^{27}$. No fue raro que los continos ocuparan después de un tiempo cargos más elevados, como fue el caso de nuestro personaje.

El 15 de marzo de 1498 Sancho de Paredes fue asentado en el Libro de asientos de los gastos de la reina doña Isabel como teniente de la camarera Inés Manrique, marquesa de Moya, con una ración de 30.000 maravedís $^{28}$, a los que se le añadieron otros 10.000 por ayuda de $\operatorname{costa}^{29}$. Su esposa Isabel Cuello también fue asentada en el Libro para custodiar las cosas de la cámara de la reina, con una ración de 15.000 maravedís anuales ${ }^{30}$, más otros 25.000 anuales que recibiría del despensero para su manutención ${ }^{31}$.

Por decisión de la reina, ellos fueron nombrados para sustituir paulatinamente a los anteriores tenientes de camareros, Martín y Beatriz, como narra el mismo Sancho de Paredes en la crónica que redactó sobre su familia, los Golfines:

Y yo casé con Ysabel Cuello, fija de Martín Cuello y de Beatriz de la Peña, camareros de la reyna doña Ysabel nuestra señora, de quien asy mismo fuymos nosotros camareros en vida de los dichos nuestros padres porque su alteza lo quiso asy, porque ellos estavan ya cansados ${ }^{32}$.

Para incrementar sus ingresos, los monarcas le beneficiaron con varias mercedes, como el nombramiento de regidor de Cáceres $^{33}$, la tenencia de la fortaleza de $\operatorname{Rojas}^{34}$ y de las fortalezas de Hoyales, Ventosilla y Fuentelisendo ${ }^{35}$, la escribanía de rentas de Plasencia,

26 TPGB, CA. 54/038. Cobró esta ración y quitación de contino hasta la muerte de la reina Isabel en 1504. Cf. AGS,EMR,CON,07,025. Tras la muerte de la reina Isabel, Juana le nombrará de nuevo contino de su casa con el mismo salario: TPGB, CA. 54/035.

27 Ladero Quesada, La España de los Reyes Católicos, p. 207. Fernández de Córdova, La Corte de Isabel I. Ritos y ceremonias de una reina (1474-1504), p. 173. Cf. GARcía AlCÁzAR, "Los «continos» reales de Castilla durante la Baja Edad Media. Estado de la cuestión".

28 TPGB, CA. 54/023. AGS,CSR,LEG.43-212, fol. 103r. 1498, marzo, 15. Véase el Documento 3 del Apédice Documental. Para abundar en más datos biográficos cf. Cf. Ortí Belmonte, "Cáceres bajo la Reina Católica y su camarero Sancho Paredes Golfin”, Mogollón CANO-Cortés, "Arte y poder de las familias hidalgas cacereñas en tiempos de Fernando el Católico. El Palacio de los Golfines de Abajo", "Símbolos e imágenes de la fachada de la casa del camarero Sancho de Paredes en Cáceres".

29 TPGB, CA. 54/044. AGS,CSR,LEG.43-212, fol. 103v. 1498, marzo, 15.

30 TPGB, CA. 54/022. AGS,CSR,LEG.43-212, fol. 104r. 1498, marzo, 05. Documento 1.

31 TPGB, CA. 54/043. 1498, marzo, 12. Documento 2.

32 TPGB, CA. 61/001, fol. 5.

33 AGS, RGS, LEG, 148907,45. 1489, julio, 31. Jaén.

34 TPGB, CA. 54/008; CA. 54/058. 1504, noviembre, 06. Medina del Campo. Con 30.000 mrs. de salario.

35 TPGB, CA. 54/064. 1504, junio, 23. Mejorada. 
Coria, Trujillo y Cáceres $^{36}$, la licencia para fundar mayorazgo con su mujer ${ }^{37}$... Además de nombrar pajes y damas a su numerosa prole, nada menos que dieciséis hijos ${ }^{38}$.

Sancho de Paredes gozó de la más íntima confianza de la reina Isabel, hasta el punto de que fue "llamado et rogado" como uno de los siete testigos para el otorgamiento de su testamento el 12 de octubre de 1504 que refrendó con estas palabras:

Yo Sancho de Paredes, camarero de la reyna nuestra señora, fuy presente por testygo al otorgamyento que su altesa hyso de este testamento y se lo vy fyrmar de su nombre y lo vy sellar con su sello y porque es verdad lo firmé de my nombre y lo sellé con my sello. Sancho de Paredes ${ }^{39}$.

Este matrimonio ocupó el puesto de camareros de la reina hasta la muerte de Isabel I. Sancho fue nombrado inmediatamente después contino de la reina Juana ${ }^{40} \mathrm{y}$, con su mujer ${ }^{41}$, camareros del infante Fernando ${ }^{42}$; asimismo, dos de sus hijos fueron elegidos continos de la casa del infante. Sancho de Paredes ocupó el oficio de camarero del infante hasta 1517, que partió por deseo de su hermano Carlos V fuera de los territorios peninsulares; en retribución por los servicios prestados a la reina Isabel y al infante Fernando como camarero, se le concedió una merced de 60.000 maravedís anuales y vitalicios ${ }^{43}$.

\section{Los escribanos de la cámara y los libros de la cámara}

El camarero era el máximo responsable de todo lo que había en la cámara y sus movimientos. Para llevar buen cuidado de la ingente cantidad de objetos que componían la cámara, era imprescindible la labor de los "escribanos de la cámara" o "de las cámaras", que tenían por cometido tomar cuenta y llevar el control de todo lo que entraba y salía por medio de los libros de la cámara ${ }^{44}$. "Este era oficio muy nesçesario en la

\footnotetext{
AGS, CCA, CED, 9,182,2. 1504, julio, 31. Medina del Campo.

AGS, CCA, CED, 5,232,2. 1501, septiembre, 03. Granada.

38 En la historia que hace Sancho de Paredes de su linaje, menciona el nombre de sus dieciséis hijos habidos en el matrimonio con Isabel Cuello: TPGB, CA. 61/001, fol. 5. Se conservan también los albalás de merced de paje o dama a los distintos hijos: TPGB, CA. 54/24-32.

39 AGS,PTR,LEG,30-2, cubiertas. Los testigos, aparte de Sancho de Paredes, fueron Juan Rodríguez de Fonseca, obispo de Córdoba; Fadrique de Portugal, obispo de Calahorra; Valeriano Ordóñez de Villaquirán, obispo de Ciudad Rodrigo; el doctor Martín Fernández de Angulo, arcediano de Talavera y del Consejo Real; el Doctor Pedro de Oropesa, del Consejo; y el Licenciado Luis Zapata, del Consejo también.

40 TPGB, CA. 54/035. 1505, abril, 22. Toro.

41 TPGB, CA. 54/033. 1505, abril, 09. Toro.

42 TPGB, CA. 54/034. 1505, abril, 09. Toro.

43 AGS,EMR,MER,176,18. 1518, abril, 25.

44 Cañas Gálvez ha estudiado magistralmente la cámara de los reyes de Castilla en la Baja Edad Media y afirma que desde el siglo XIV contó con una estructura administrativa definida y estable. Cf. CAÑAS
} 
Casa real, para lo que conviene a la buena cuenta del camarero" ${ }_{45}$. Era trabajo muy bien considerado, podemos decir que el más importante después del camarero a tenor de sus remuneraciones:

Es el ofiçio y ofiçial segundo en la cámara, porque de todo lo que entra en ella e sale della ha de tener razón e cuenta, e cómo se trae o se lleva, e lo ha de firmar en el libro manual - alias borrador- que tiene a su cargo el moço de cámara de las llaves della, así del resçibo como de la dacta; así que ofiçio es este de mucha confiança e crédito; e hállase en las compras de lo que a la cámara viene, de paños, olandas, sedas, brocados e otras cosas muchas de qualquier género que sean. E conviene que sea escrivano de los reinos, porque algunas vezes es menester que dé fe de algunas cosas e signe algunos auctos e escripturas; e es muy útil ofiçial, e ha de tener buen salario e raçiones, así de quitaçión, como en la despensa, e çera para su ordinario gasto e serviçio de su casa. [...] Creer se deve que el salario sería bastante para se sostener su persona e casa; porque el ofiçio en sí requiere que esté en persona de auctoridad e de buenas habilidades e diligençia, e que tenga buena pluma e sea sufiçiente arismético o contador, e cursado en las cosas de la cámara, e que no se descuide con su ofiçial, e que vea a menudo sus libros; y consejarle hía yo que toviese uno e aun dos conformes al borrador e al mayor que ya tengo ya dicho, pero que ese libro mayor no le escusase de hazer otro de pliegos horadados en que cada género de cosas estoviese separado. Serviría aquesto que cuando Vuestra alteza quisiese ver particularmente un género de cosa alguna de su cámara, sin le llevar el libro mayor pudiese satisfazer con llevar el pliego horadado en que aquella cosa estoviese, e no otra alguna ${ }^{46}$.

Estos libros eran para el camarero su principal instrumento de trabajo porque contenían el inventario de todo el patrimonio real de la cámara y con ellos controlaba todo lo que estaba a su cargo. Por ello tenía que cuidar que los escribanos de la cámara pusieran todo el empeño y cuidado en su elaboración. Tan importantes y necesarios eran los libros, que se conservaban bajo llave, custodiados por el mozo de cámara que "tiene las llaves della". Tener los libros en buen estado y actualizados era muestra de que el camarero estaba ejerciendo bien su oficio ${ }^{47}$.

\footnotetext{
GÁlVEz, "La cámara de Juan II: vida privada, ceremonia y lujo en la corte de Castilla a mediados del siglo XV", p. 92; - Burocracia y Cancillería en la corte de Juan II de Castilla (1406-1454). Estudio institucional y prosopográfico, pp. 151-153.

45 Fernández de Oviedo y Valdés, Libro de la Cámara Real del príncipe don Juan, p. 115.

46 Ibidem.

47 Fernández de Oviedo y Valdés, Libro de la Cámara Real del príncipe don Juan p. 98: "[los libros son] la llave prinçipal de su cuenta, e en lo que él hace tener mucha vigilançia e atençión, porque en esto
} 
En 1498 figuraban hasta seis escribanos de la cámara de la reina Isabel I de Castilla: Diego Ramírez, Diego Cano, Diego de Medina, Diego de Salinas, Juan de Cabrera y Francisco de Hermosilla con quitaciones variables entre 30.000 maravedís el primero y 5000 maravedís el último, lo que nos hace suponer que el primero y que más cobraba era el director y responsable de esta tarea ${ }^{48}$. A partir de la segunda mitad de 1502 parece que tomó la dirección Suero de Cangas ${ }^{49}$, quizá por defunción de Diego Ramírez $z^{50}$.

\section{Los libros de Sancho de Paredes en el palacio de los Golfines de Abajo}

Al dejar la Corte Sancho de Paredes se trajo una serie de libros que habían sido como su instrumento de trabajo. Aprecio les tributaba el camarero, hasta el punto de mandarlos encuadernar casi todos como si fueran ejemplares valiosos. Son los diez libros de cuentas o inventario de la cámara con su manual, un libro de mandatos de la reina, otro libro de la testamentaría de la reina y el libro de finiquitos.

\subsection{Libros de cuentas de la cámara o inventario}

Ortí Belmonte afirmó en su artículo que "en 1498 fue nombrado teniente de camarero Sancho Paredes Golfín y en 2 de abril del mismo año ya está terminado el inventario de lo que existía en la cámara de la Reina, dando lugar al primer Libro de cámara"s1. Esto no es del todo exacto, como ahora veremos.

Los libros de cuentas o inventario enumeran los objetos que estaban en la cámara de la reina. Están diversificados por materias y numerados, numeración que debieron llevar en la tapa anterior, pero que ya no la podemos apreciar porque fueron reencuadernados con cuero marrón. En su origen todos llevaron encuadernación en cartera, de pergamino y con refuerzos de cuero, la que habitualmente se utilizaba en este tiempo para la documentación administrativa y que aún portan el Libro Manual y los libros de Finiquitos de dineros, de Mandatos y de Testamentaría ${ }^{52}$. En alguno de los libros de inventario lo podemos observar todavía, pues la actual encuadernación mudéjar de cuero está sobrepuesta y pegada sobre la anterior de pergamino ${ }^{53}$. Muy probablemente, Sancho de Paredes, mandó encuadernar en piel estos libros, dándoles una mayor dignidad una vez abandonada la corte.

consiste hazerse mejor el serviçio de Su Alteça, e la limpieça e verdad que deve aver en su cuenta e en tal prinçipal e preeminente ofiçio, e tan junto a la persona real e a su cámara”.

48 González Marrero, La casa de Isabel la Católica, p. 46.

49 AGS,CCA,CED, 6,77, 205, 206, 225. AGS,CSR,LEG.103,163.

50 En el Libro de asientos de los gastos de la reina doña Isabel se le deja de librar su correspondiente ración y quitación a partir de 1503: AGS, CSR, LEG. 43-212, fol. 115.

51 Ortí Belmonte, "Cáceres bajo la Reina Católica y su camarero Sancho Paredes Golfin”, p. 264.

52 Carpallo Bautista, "La encuadernación del libro en la Edad Media", p. 240.

53 Así lo encontramos en el Libro Segundo. 
Cada uno de los distintos objetos de la cámara de la reina, ya sean joyas, vestidos, mobiliario, libros, etc., viene descrito de una forma sucinta para poder ser reconocido en caso de tener que ser buscado, con informaciones adicionales como fecha y el lugar de la recepción de dicho objeto, persona que lo entregó y modo de adquisición, bien compra, bien regalo, bien entrega. Correspondía a los escribanos de la cámara tomar nota de todos estos datos ${ }^{54}$.

El método de contabilidad de estos objetos en la cámara es el de "cargo y data", el más usual para rendir cuentas. Consistía en poner en "cargo" el bien recibido al gestor o administrador (en este caso el camarero), siendo el descargo o "data" la demostración de haber devuelto o pagado ese bien. Cuando lo entregado era menor que lo recibido se producía el "alcançe", que quedaba en contra del gestor al que se le tomaba cuenta, contrayendo la obligación de hacer depósito del bien o del importe de la diferencia. Saldado el alcance, el interesado recibía su correspondiente carta de finiquito o fenecimiento de cuentas de parte de la Contaduría Mayor de Cuentas. En el caso particular de los bienes de la cámara, el "cargo" se hacía cuando, al recibir el camarero el bien en cuestión de manos de la reina o de cualquier otro en su nombre, el escribano de la cámara escribía en el libro los descriptores mencionados del objeto y daba fe con su firma de la entrega; la "data" o descargo del objeto, siempre por mandato de la reina a través de una cédula real ${ }^{55}$, quedaba recogida bajo el cargo. En los libros vemos las firmas de Diego Ramírez en los cargos desde el comienzo de los mismos, en abril de 1498, hasta la primera mitad de 1502, momento a partir del cual firma los cargos Suero de Cangas, su sucesor en el oficio ${ }^{56}$.

Hay cargos desde la primavera de 1498 hasta la muerte de la soberana el 26 de noviembre de 1504, fecha en la que podemos decir que se concluyeron los libros de inventario, pues a lo largo de todos estos años se estuvieron cargando objetos a Sancho de Paredes.

Todos los libros llevan en uno de los folios iniciales el índice con la enumeración de las distintas partidas de objetos que conforman dicho libro y en el verso de ese mismo folio o en el siguiente la validación de la Audiencia de la Contaduría Mayor de Cuentas rubricada por tres oficiales, Beltrán del Salto y Alonso Ruiz, lugartenientes de los dos

\footnotetext{
${ }^{54}$ Fernández de Oviedo explicó como se hacía el registro de las telas y brocados en la cámara del príncipe Juan: "De los brocados, e sedas, e olandas e todo lo que va a la cámara, delante del camarero se hazen los presçios, e el escrivano della haze cargo al camarero en el libro de la cámara, que está en poder del camarero o del que en su nombre tiene las llaves e lo resçibe; e otra tal partida como firma el escrivano de la cámara, firma el que lo resçibe en el libro del escrivano de la cámara, e así como la pieça de brocado, o seda, o paño o olanda - o lo que es - entra en la cámara, el de las llaves le pone cosido un papel en la cabeça o pie de la pieça que dize así: Esta pieça de tal seda — o lo que ella es - entró en esta cámara de Su Alteza tal día, e mes e año. Compróse de tal mercader, a tal preçio, como paresçe en el libro manual de la cámara en tal hoja. Tiene tantas varas." Fernández de Oviedo y Valdés, Libro de la Cámara Real del principe don Juan, p. 98.

55 Más de doscientas cédulas reales originales de este estilo dirigidas a Sancho de Paredes entre los años 1498 y 1504, las encontramos en los legajos AHN,DIVERSOS-COLECCIONES, 246, 288, 289 y 290.

56 Cf. nota 48.
} 
contadores mayores de cuentas, y Andrés Martínez escribano de la Audiencia. En todos se utiliza la misma fórmula:

Todo lo contenido en este libro que está señalado por pasado en cuenta de las señales de Beltrán del Salto, o de Alonso Ruyz o de Andrés Martínez se pasó en cuenta al camarero Sancho de Paredes e a Ysabel Cuello su muger por nóminas e çédulas de la reyna nuestra señora e todo ello fue puesto en el fin e quito que se dio a los dichos Sancho de Paredes e su muger.

Beltrán del Salto, Alonso Ruyz, Andrés Martínez [rúbricas].

Con estas palabras, los mencionados oficiales testimoniaron que, tras la muerte de la reina, habían verificado en los libros que todas las cosas cargadas a Sancho de Paredes e Isabel Cuello tenían su descargo correspondiente, con el fin de poder obtener el finiquito los camareros.

\subsubsection{Libro Manual57.}

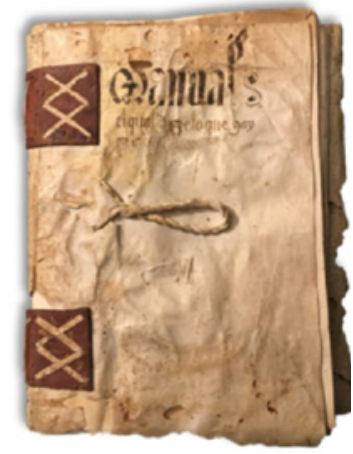

Lleva encuadernación mudéjar de cartera, de pergamino flexible, con refuerzos de cuero en tira, con solapa que sale de la tapa posterior y se coloca sobre la frontal para cerrar, con un cierre de botón y ojal de piel blanca. Tiene unas dimensiones de 160 x $210 \mathrm{~mm}$. y 44 folios.

Este libro se trata de un epítome de los once libros de inventario. Con estas palabras de la cubierta anterior, a modo de título, se describe el contenido de este instrumento: "Libro Manual el qual dize lo que hay en los dichos libros", o con estas otras del encabezamiento del primer folio se especifica un poco más: "Los libros que ay en la cámara de la rreyna nuestra señora de los quales en este libro se pone la memoria como se han de granjear e an de ser conosçidos, que es en la manera siguiente". En definitiva, no es más que un compendio de los índices de los once libros de cuentas de la cámara o inventario que existieron.

En una segunda parte del Libro Manual encontramos una tabla de equivalencias para tasar en maravedís las joyas de oro, según su quilataje y peso (marco, onza, ochava, tomín, grano). El escribano introduce estas tablas con las siguientes palabras: "Regla para saber quánto vale qualquier marco de oro, de qualquier ley que sea, a dinero, desde veynte e quatro quilates hasta doze" (7 folios). A continuación viene una regla mucho más complicada para tasar la plata según su ley ( 5 folios) y por último una "Regla para

57 TPGB, CA. 68/001. 
hundir oro de muchas leyes" (1 folio) ${ }^{58}$. Con estas tablas el escribano de la cámara y el camarero podían comprobar si las tasaciones de los objetos de material noble estaban bien tasados, e incluso tasarlos ellos mismos.

\subsubsection{Libro Primero: oro y plata en pasta, piedras, perlas y aljófar ${ }^{59}$}

Solo se conservan 23 folios de este Libro Primero, cosidos en un cuaderno facticio, que encontramos al abrir el Libro Séptimo. En el primer folio está el índice del libro, el mismo que encontramos en el Libro Manual, que describe el contenido del libro así:

En el libro primero es en el que se asientan todas las cosas de oro e plata en pasta que son para hundir, e piedras, e perlas, e aljófar por engastar, las quales dichas cosas están puestas en este dicho libro en cinco partidos en esta manera:

El primero es de oro, a cartas una

El segundo que es de plata, a cartas çiento e onse

CXI

El tercero es de perlas, a carta dozientas e siete

El quarto ques de aljófar, a cartas trezientas e çinquenta e una CCCLI

El quinto es de piedras, a cartas quatroçientas e diez e seys

CCCCXVI

Si este libro tenía cinco partidos, y cada partido extendía su contenido a lo largo de cien folios aproximadamente, comenzando el último partido en el folio número CCCCXVI, podemos suponer que este volumen tendría, al menos, quinientos folios, por tanto, era un ejemplar voluminoso. En la actualidad el cuaderno facticio contiene los únicos veintitrés folios conservados del Libro Primero: 1-12.208.216-223.351-352.

En el segundo folio hallamos la validación del contenido de todos los libros hecha por el escribano de cámara, Diego Ramírez. Es interesante porque da una serie de datos de la génesis de estos libros, el modo de gestión administrativa de las cosas de la reina, los primeros escribanos de la cámara que iniciaron el trabajo, y el lugar y tiempo en que se incorporó él, por mandato de la reina, para revisar todo lo realizado por los anteriores:

Yo Diego Ramírez, escrivano de cámara de la Reyna nuestra señora doy fe en como todas las cosas que en este libro que es el primero de los libros de la cámara de su alteza que en él están cargadas e descargadas a Sancho de Paredes e a Ysabel Cuello, su muger, camareros de su alteza, que van todas fyrmadas de mi nombre; en como yo por mandado de su alteza les fise cargo de todas ellas e gelas descargué asimismo por sus nóminas y

\footnotetext{
581 marco de plata $=8$ onzas; 1 onza $=8$ ochavas; 1 ochava $=6$ tomines; 1 tomín $=12$ granos. De otra manera, 1 marco de plata $=8$ onzas, 64 ochavas, 384 tomines, 4608 granos.

59 TPGB, CA. 68/002.
} 
çédulas firmadas del real nombre de su alteza e refrendadas de sus secretarios e con conosçimientos de las personas a quien se mandavan dar las que de todo punto salen de la dicha cámara e las otras con mandamiento de su alteza vocal, segund e de la forma e manera que en este libro van asentadas, de las cuales algunas de ellas le estaban cargadas, antes que yo viniese a servir en este ofiçio de escrivano de la cámara, por Diego de Medina, e Françisco de Hermosilla e Diego de Salinas, escrivanos de cámara de su alteza, las quales los dichos Sancho de Paredes e Ysabel Cuello su muger ovieron reçebido de Beatriz Cuello camarera de su alteza e de otras personas así en la villa de Alcalá de Henares como en las cibdades de Toledo, e Çaragoça, como en las villas de Madrid, e Ocaña, las quales yo corregí e conçerté con los libros donde los susodichos escrivanos las tenían cargadas a los dichos Sancho de Paredes e Ysabel Cuello su muger, las quales dichas cosas por mandado de su alteza yo las torné a ver todas [e] cada una por si, e las que heran de pesar las pesé, e las que heran de medir las medí, segund y en la manera que aquí en este dicho libro van asentadas y asimismo todas las otras cosas que después que yo vine a servir a su alteza en el dicho ofiçio que fue en la çibdad de Çaragoça a primero día del mes de setienbre de mill e quatroçientos e noventa e ocho años e les fise cargo a los susodichos e asimismo gelas descargué segund e de la forma e manera que en este dicho libro van asentadas e declaradas en todos los partidos que en él están firmados de mi nombre, lo qual todo yo fize por mandado de la reyna nuestra señora e seyendo presente a todo ello así quando se les faze cargo de las cosas que se an de cargar, como a las que han de dar e dan por nóminas e çédulas e mandamientos de su alteza como a las otras que se cortan e hunden o mudan de una cosa en otra sin salir de la dicha cámara, como dicho es. E por que todo lo susodicho pasa en rrealidad de verdad como dicho es este dicho libro e los otros de la cámara, se an así granjeado e granjean en la forma susodicha, asenté esta fe firmada de mi nombre en comienço deste dicho libro.

Afirma aquí Diego Ramírez que los cargos a Sancho de Paredes e Isabel Cuello de las cosas de la cámara de la reina comenzaron a hacerse en Alcalá de Henares, siendo Diego de Medina ${ }^{60}$, Francisco Hermosilla ${ }^{61}$ y Diego de Salinas ${ }^{62}$ los que tomaban nota en los libros. El primero de los escribanos estaba asentado en el Libro de asientos

\footnotetext{
${ }_{60}$ AGS, CSR, LEG. 43-212, fol. 92v. Diego de Medina fue asentado como escribano de las joyas el 15 de febrero de 1475 con una ración de 11.200 mrs. anuales, que se vieron incrementados a partir de 1482 a $21.200 \mathrm{mrs}$. Fueron librados hasta 1500.

${ }_{61}$ AGS, CSR, LEG. 43-212, fol. 93. Francisco de Hermosilla fue asentado como escribano de la cámara el 27 de agosto de 1493 con 16.000 mrs. de ración, librados hasta 1500 .

62 AGS, CSR, LEG. 43-212, fol. 100. Diego Salinas fue asentado como escribano de la cámara el 08 de julio de 1486 con una ración de 10.000 mrs. que se le acrecentaron en 20.000 a partir de 1501 .
} 
de los gastos de la reina doña Isabel desde 1475 con el cargo de "escribano de las joyas" y era el que tenía la "raçión y quitación" más alta, 21.200 maravedís. Los otros dos ejercían como escribanos de las cámaras desde 1486 y 1493 respectivamente, cobrando más Hermosilla que Salinas. Diego Ramírez comenzó a trabajar por mandato de la reina Isabel como fedatario de la gestión de sus bienes el 1 de septiembre de 1498 en Zaragoza, aunque no se le asentó como escribano de la cámara hasta el 20 de noviembre de ese mismo año en Ocaña ${ }^{63}$. La reina católica le encomendó la misión fundamental de dirigir la elaboración de los libros de la cámara y aportar un criterio sistemático a la gestión.

\subsubsection{Libro segundo: joyas de oro y plata ${ }^{64}$}

Encuadernado con tapas de madera forradas con piel y dos abrazaderas de correa para mantener cerrado el libro. Sus dimensiones son 360x250 mm. Tiene 472 folios.

El Libro Segundo es de joyas con once partidos: $1^{\circ}$ - "joyeles, coronas, rosas e ramos". $2^{\circ}$ - "collares, cadenas e gragantillas". $3^{\circ}$ - "çintas e texillos de oro e plata e guarniciones de çintas". 40- "manillas, axorcas, braçaletes e sortijas". $5^{\circ}$ - "cuentas e pomas e cruzes e ymagines e anusdeys e tiras de cabeça e tocadillos e arracadas e gorgueras e cuernos de olicornio". $6^{\circ}$ - "saleros e copas e vasos e almarraxas e calderetas e barrilicos e libros e esmaltes e candadicos e caços". $7^{\circ}$ - "cofres e caxicas e ventalles". $8^{\circ}$ - "capilla rrica e candelericos e rrelojes". $9^{\circ}$ - "rropas de vestir con chapería". $10^{\circ}$ - "piedras e perlas engastadas por si". $11^{\circ}$ - "engastes de joyeles e de otras qualesquier cosas e sortijas e chaperías e qualesquier cosas menudas de oro que no están en ningún partido de los sobredichos".

En todos los libros de cuentas o inventario, encontramos entre partido y partido muchos folios en blanco, hasta el punto de que es casi la misma cantidad de folios escritos que sin escritura, es decir, que la confección inicial del libro se hizo previendo los futuros cargos.

En este libro cada cargo lleva, aparte de la persona que entrega la joya, la fecha, el lugar y la descripción de esta, su peso, quilataje y tasación en maravedís.

\footnotetext{
63 AGS, CSR, LEG. 43-212, fol. 115: "Diego Ramírez asentó con la reyna nuestra señora en Ocaña a 20 de noviembre de XLVIII años. Tiene de su alteza de raçión e quitaçión en cada un año por escrivano de las cámaras treynta mill mrs. que an de ser librados de primo de setienbre del dicho año en adelante según se contiene en un alvalá firmado de su alteza fecho el dicho día".

${ }^{64}$ TPGB, CA. $68 / 003$.
} 


\subsubsection{Libro tercero: plata labrada ${ }^{65}$}

Encuadernado en piel sobre papelón, en forma de cartera, con lacerías estampadas en frío muy similares a las del Libro Segundo. Ha perdido la solapa que se coloca sobre la tapa anterior. Sus medidas son $340 \times 240 \mathrm{~mm}$. y tiene 258 folios.

Este libro solo tiene tres partidos, $1^{\circ}$ - "plata de capilla"; $2^{\circ}$ - "plata de majar" y $3^{\circ}$ - "cosas menudas de plata".

En este libro también cada pieza lleva, por lo general, su quilataje y tasación en maravedís ${ }^{66}$.

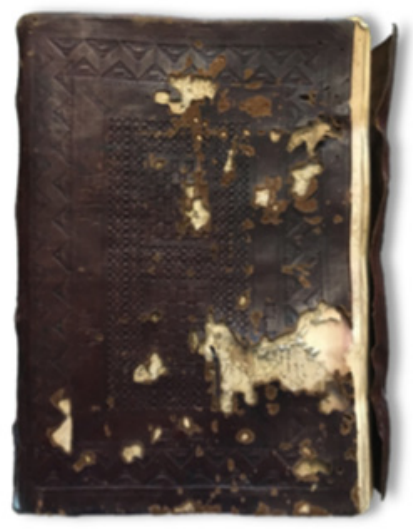

\subsubsection{Libro quarto: tejidos bordados y brocados, terciopelos y sedas ${ }^{67}$}

Encuadernación de cartera en cuero, cierre de cinturón y hebilla. Sus dimensiones son de 310x240 mm. y 630 folios.

Este libro tiene diecisiete partidos: $1^{\mathrm{o}}$ - "chapados e cosas bordadadas" (sic), $2^{\circ}$ - "tiras de oro tirado e plata tirada", $3^{\circ}$ - "tela de oro tirado", 40 - "brocado de oro tirado", 50- "brocados de pelo", 60 - "brocado damasco", $7^{\circ}$ - "brocados rasos", $8^{\circ}$ - "villudo villotado", $9^{\circ}$ - "villudo villutado o carmesí", $10^{\circ}$ - "terciopelo carmesí", $11^{\circ}$ - "azeytuníes carmesís e de colores", $12^{\circ}{ }^{\circ}$ "terçiopelo negro", $13^{\circ}$ - "terciopelo de colores", $14^{\circ}$ - "çetines carmesíes", $15^{\circ}$ - "çetines de colores", $16^{\circ}$ - "damascos" y $17^{\circ}$ - "sedas de tripol".

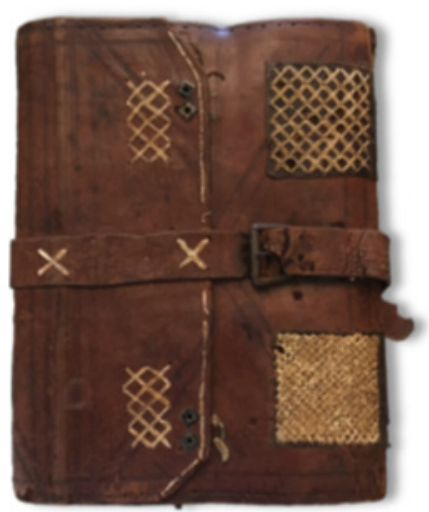

\footnotetext{
65 TPGB, CA. 68/004.

66 En el Archivo General de Simancas, con signatura CMC,1EP,LEG.93, encontramos un libro de inventario, con unas dimensiones de 340-250 mm. y 117 fols. En la tapa anterior está escrito "Libro del cargo de Sancho de Paredes e Ysabel Cuellar (sic) su muger, camareros de la rreyna cathólica". Tiene encuadernación mudéjar de cartera, de pergamino amarillento, con una solapa sobre el corte frontal, que sale de la tapa posterior y se coloca sobre la frontal, con refuerzos de cuero en tira, con restos de cierres de botón y ojal de cuero blanco. En el primer folio aparece a modo de título "Cargo contra Sancho de Paredes e Ysabel Cuello su muger, camareros de la Reyna nuestra señora", con los mismos partidos que el Libro Segundo y el Libro Tercero del archivo de los Golfines de Abajo que acabamos de ver. El formato es muy similar, en forma de cargo y data, pero, a diferencia de los libros anteriores, los cargos vienen firmados por Sancho de Paredes y las datas, por lo general, por Diego Ramírez.
}

67 TPGB, CA. 68/005. 


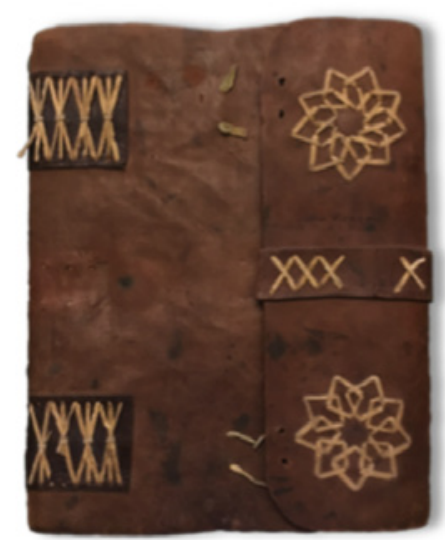

\subsubsection{Libro quinto: telas y paños ${ }^{68}$}

Encuadernación de cartera en cuero, con dos refuerzos de cuero en tira y con cierre de hebilla, esta perdida. $300 \times 240 \mathrm{~mm}$. y 407 folios.

Este libro tiene trece partidos: $1^{\circ}$ - "chamelotes de seda", $2^{\circ}$ - "chamelotes de lana", $3^{\circ}$ - pannos de grana", $4^{\circ}$ - "paños de colores", $5^{\circ}$ - "paños negros", $6^{\circ}$ - "terçeneles e tafetanes", $7^{\circ}$ - "fustedas", $8^{\circ}$ - "estameñas negras", $9^{\circ}$ - "çenefas de qualquier manera", $10^{\circ}$ "guarniciones de frontales e doseles", $11^{\circ}$ - "texillos en pieça e sin guarniciones", $12^{\circ}$ - "paños gruesos, fajas e sayales", $13^{\circ}$ - "peñas en pieça nuevas".

\subsubsection{Libro sesto: tocados, manteles, lienzos, $\operatorname{cintas}^{69}$}

Encuadernación de cartera en cuero con cierre de hebilla y dos refuerzos en el lomo de cuero en tira. $300 \times 240 \mathrm{~mm}$. y 355 folios.

En este libro los cargos contienen en las descripciones de cada tejido las varas de largo y de ancho, medida que se anotan igualmente en el margen de cada uno.

Según vemos en el índice de primer folio, este libro tuvo trece partidos, pero en la actualidad el último se ha perdido. Son los siguientes: $1^{\circ}$ "de tocas e seda rrasa en pieça", $2^{\circ}$ - "manteles e tovallas", $3^{\circ}$ - "olandas", $4^{\circ}$ "lienços blancos e navales", $5^{\circ}$ - "angeos e bitres", $6^{\circ}$ - "lienços tennidos e bocaranes", $7^{\circ}$ - "flocaduras de oro e seda e hilo", $8^{\circ}$ - "randas de oro e seda e hilo e rredes de hilo e oro e plata", $9^{\circ}-$ "çintas e rrandas de seda",

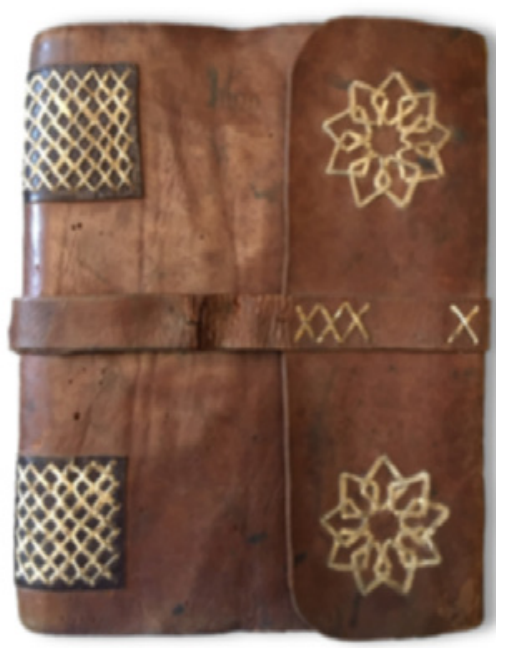
$10^{\circ}$ - "oro hilado fino", $11^{\circ}{ }^{-}$"seda en hilo torçido e floxa", $12^{\circ}$ - "plata hilada", $13^{\circ}$ - "de todo hilo".

\footnotetext{
68 TPGB, CA. 68/006.

69 TPGB, CA. 68/007.
} 
5.1.7. Libro seteno: ropa de vestir, ropa blanca, atavíos de andas, sombreros y calzado ${ }^{70}$

Encuadernación de cartera en cuero con cierre de hebilla. 350x270 mm. y 459 folios.

Este libro según el índice y el Libro Manual tuvo cinco partidos, ahora solo se conservan cuatro, pues el último se ha perdido. Son los que siguen: $1^{\circ}{ }^{-}$"de qualesquier rropas de vestir", 20 - "de rropa blanca", 3․ "de guarniçiones e atavíos de andas", 4_ "sombreros e capirotes e bonetes e tocas e almayzales"; el $5^{\circ}$ nos muestra el índice que era "de cueros e

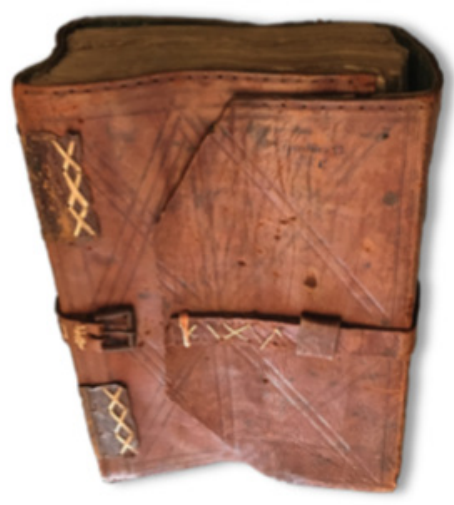
borzeguíes e otras cosas de calçado e alcorques e chapines".

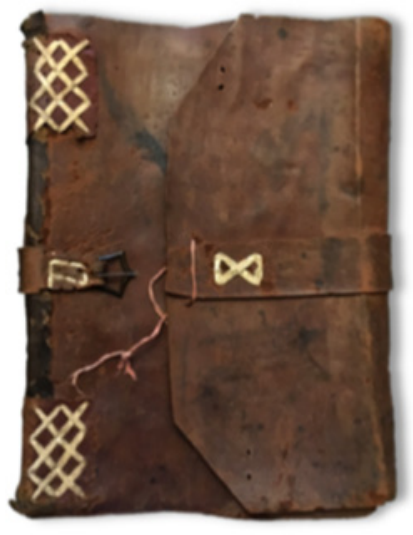

5.1.8. Libro otavo: ornamentos textiles, doseles, tapices, alfombras y cosas de camas $^{71}$

Encuadernación de cartera, en cuero marrón con cierre de hebilla y dos refuerzos de cuero en tira. 360x260 mm. Cuenta con 318 folios.

Estas son las partidas del libro octavo: $1^{\circ}$ - "ornamentos", $2^{\circ}$ - "doseles e sitiales e cortinas e almohadas", $3^{\circ}$ "pannos de devoçión", 4- "pannos de rras", 5- "alhombras e rreposteros", y 60 - "cosas de camas".

5.1.9. Libro noveno: corales, perfumes, trozos de brocados, almohadas, armas, libros cajas, arcas y cofres, instrumentos de música y pieles $^{72}$

Encuadernación de cartera, en cuero marrón, con una solapa sobre el corte frontal, que sale de la tapa posterior y se coloca sobre la frontal, con refuerzos de cuero en tira. Tuvo cierre de hebilla, perdida en la actualidad. 350x250 mm. y 272 folios.

Son siete los partidos que encontramos en este libro, a saber: $1^{\circ}$ - "menjui e anime e anbar fino e cuentas e corales e perfumes e alizcle e algalía e otras cosas de

\footnotetext{
TPGB, CA. 68/008.

TPGB, CA. 68/009.

72 TPGB, CA. 68/010.
}

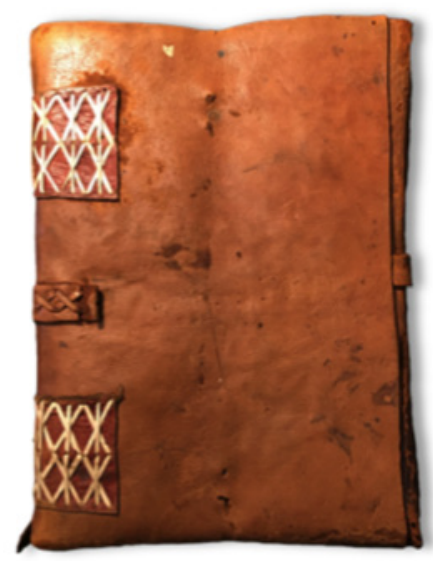


olores", 20 - "tiras e pedaços de brocados e terçiopelos e rrasos e damascos e pannos e otras cosas", 30 - "guadameçíes e almohadas de guadameçíes", 4- "cosas de armas", 5- "libros", 60 - "pargaminos e lienços de pinturas e devoçión e cofres e arquillas e caxas e tableros de axedrez e escudillas e cucharas de palo e arcas e pendones e guiones e jarras e copas de vidro relojes e marcos e rretablos e bolsas de seda e cueros e tahelíes e papeles con rreliquias e peynes e escrivanías e rropetas de momos e cascaveles e portacartas e atabales e claviorganos e claveçínbalos e monacordios e anafiles e bozinas de vidro e carnieles e çintos de seda e cuero e mesas e vancos e cruzes de latón e campanillas e vinajeras e portapazes e hilo e agujas e alfileres e hierros para ostias e esteras e otras menudençias", $7^{\circ}$ - "enforros de conejos e peñas de armiños e martas e cabritas, los quales son fechos en ropas o pedaços para rropas por que en el libro quinto se pone en los que vienen en pieças”.

\subsubsection{Libro Dezeno: dineros de la cámara ${ }^{73}$}

Aunque en el Libro Manual se habla de un "Libro Dezeno, el qual es de dineros de la cámara que se an rreçebido e el gasto dellos como se an dado por nóminas e çédulas de la rreyna nuestra señora" ${ }^{74}$, sin embargo, Ortí Belmonte solo mencionó hasta el Libro Noveno al estudiar estos libros de la cámara. El historiador expresaba en su artículo que "falta el Libro séptimo, pero hay otro Libro con el nombre de finiquitos de cuentas aprobados por los Reyes con partidas muy curiosas, como las obras hechas en la Alhambra"75. En ningún momento menciona que este fuera el Libro Dezeno, muy probablemente porque tampoco supiera que existió un libro décimo, al no haber tenido ante sus ojos el Libro

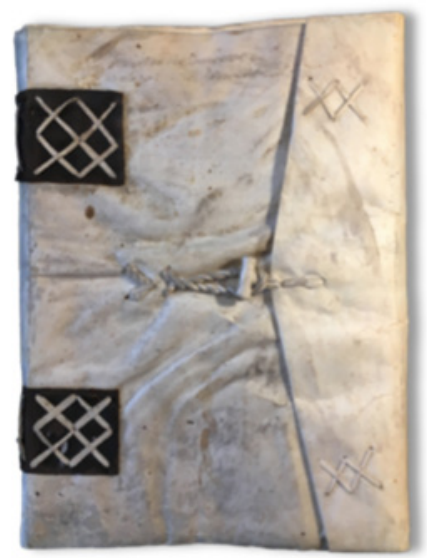
Manual, que tampoco nombra en ningún momento.

Pensamos que ese libro de "finiquitos de cuentas aprobados por los Reyes con partidas muy curiosas", que porta una encuadernación de cartera en pergamino, con dos refuerzos de cuero oscuro en tira y cierre de botón y ojal, con unas dimensiones de 300 × $230 \mathrm{~mm}$. y 86 folios, no es otro que el Libro Dezeno de la cámara de la reina Isabel. En primer lugar, porque así como el Libro Primero comenzaba con la validación de Diego Ramírez de todos los cargos y descargos de las cosas de la cámara contenidos en los libros, en este los cargos y descargos de los maravedís son validados por el mismo escribano de la cámara, por orden de la reina, el 7 de agosto de 1499:

\footnotetext{
TPGB, CA. 68/012-C.

4 TPGB, CA. 68/001, s.f.

75 Ortí Belmonte, “Cáceres bajo la Reina Católica y su camarero Sancho de Paredes Golfín”, p. 265.
} 
Yo, Diego Ramírez, escrivano de la cámara de la reyna nuestra señora, doy e fago fee en como Sancho de Paredes camarero de su alteza ha rresçibido por mandado de su alteza todos los maravedís de los cargos que en este libro están cargados que van firmados de mi nombre e ansí mismo doy fee en como el dicho Sancho de Paredes ha gastado todos los maravedís que en este libro están puestos por gasto, los quales ha gastado por nóminas e çédulas de su alteza, las quales yo vi firmadas del real nombre de su alteza e rrefrendadas de sus secretarios e los conosçimientos de las personas a quienes dieron los dicho maravedís entiendese los capítulos e planas que paresçieren firmados de mi nombre en fee de lo qual firmé aquí mi nombre que es fecha en la çibdad de Granada, a syete días del mes de agosto de mill e quatroçientos e noventa e nueve años, en el qual dicho día su alteza me mandó que yo viese todos los cargos cédulas e nóminas que su alteza dellos aya dado, e así vistos e conçertados los firmase de mi nonbre e dende en adelante los que más resçibiese e gastase los quales dichos cargos van firmados de la manera que dicha es a los gastos en fin de cada plana e en fin de cada gasto de los dichos cargos.

Este libro contiene las cuentas de ingresos y gastos en numerario revisadas y aprobadas por la Contaduría Mayor de Cuentas. Se trata de finiquitos que este organismo competente de la Corona fue dando a Sancho de Paredes a medida que la reina ordenaba a esta institución que le revisaran las cuentas de un período concreto. Cuatro son los finiquitos:

- Uno de los maravedís gestionados entre el 15 de marzo de 1499 y el 02 de noviembre de 1500 (2.395.533,5 maravedís). Tiene diez folios y comienza la foliación con el número I. Firmado el 05 de febrero de 1501 en Granada.

- Otro comprende el período comprendido entre el 25 de noviembre de 1500 y el 30 de junio de 1502 (2.044.954 maravedís), tiene once folios y se inicia la foliación con el número xv. Data del 19 de octubre de 1502 en Madrid.

- Este es del dinero movido entre el 08 de noviembre de 1502 y el 04 de diciembre de 1503 (4.824.945 maravedís); tiene tan solo tres folios y la foliación comienza con el número xxx. Está firmado el 14 de mayo de 1504 en Medina del Campo.

- Este último resulta especialmente interesante porque viene intitulado por el rey Fernando, y los recién estrenados monarcas Felipe y Juana. No está indicado el período (176.485 maravedís). Tiene únicamente dos folios, sin foliar. Firmado el 20 de diciembre de 1505 en Salamanca ${ }^{76}$.

\footnotetext{
76 Documento 5. Esta fórmula en la que los documentos reales van intitulados por los tres soberanos se utilizó después de la Concordia de Salamanca (25 de noviembre de 1505) hasta la Concordia de Villafáfila (27 de junio de 1506).
} 
La estructura de todos estos finiquitos es prácticamente igual que la de una real provisión: intitulación, dirección, notificación, exposición, disposición, fecha y validación. En la intitulación los nombres de los reyes vienen precedidos con el tratamiento de "don" y "doña", con la fórmula de derecho divino -"por la gracia de Dios"-, su cargo -"rey e reyna"- y la enumeración de sus dominios. A continuación, la dirección la expresan con la misma fórmula: "Por quanto vos, Sancho de Paredes, camarero de mí la reyna, recibistes por mi mandado çiertas contías de maravedís". En la notificación, se expone que Sancho de Paredes ha recibido como camarero una cantidad de dinero para usarla en lo que la reina indicare en un período concreto; y que a su vez la reina ha pedido que rindiera cuentas a la Contaduría Mayor de Cuentas de ese período; él ha declarado, tras hacer el juramento, lo que ha recibido y gastado mostrando los libros de cuentas, junto con las cédulas y mandatos de la reina que ordenaban gastar los distintos importes, que enumera a continuación en forma de cargo y data, que se puede prolongar por varios folios. Después se hace el balance y se señala el alcance, siempre con la fórmula: "Así que montan todos los maravedís que vos, el dicho Sancho de Paredes, mi camarero, aveys dado e pagado por mandado de mí, la reyna, en la manera que dicho es [cantidad con la suma de lo gastado], de los quales descontados los dichos [cantidad con la suma de lo entregado] maravedís que montó el dicho vuestro cargo, paresçe que aveys pagado de más [alcance o diferencia]".

A continuación viene la exposición, en la cual, a instancia del interesado, se solicita el finiquito, siempre con la fórmula: "E agora por quanto vos el dicho Sancho de Paredes, camarero de mí la reyna nos suplicastes [...] que a nuestra merçed pluguiese de vos mandar dar nuestra carta de fin e quito [...] e por quanto ante los dichos mis contadores mayores de quentas fizistes juramento que la dicha vuestra cuenta así en el cargo como en la dicha data es buena e çierta e que en ella no ovo ni ay fraude ni encubierta alguna, tovímoslo por bien".

Seguidamente, viene la disposición, en la cual los reyes aprueban las cuentas y le dan por libre y quito de todo cargo y a todos sus sucesores: "Por ende nos, los sobredichos rey don Fernando y reina doña Isabel lo amos e aprobamos la dicha cuenta, e la avemos por çierta e verdadera, e a vos damos libre e quito". Por último, se fecha con la fórmula "Dada en" a la que se añade la ciudad y el día. Estas provisiones son emitidas por la Contaduría Mayor de Cuentas, por lo cual, no tiene cláusula conminatoria.

Las cartas de finiquito vienen validadas con el sello de placa secreto o de la poridad, firmadas por los dos contadores mayores de cuentas, Rodrigo de Coalla, licenciado y Juan Alfonso Serrano, bachiller en decretos, y por sus tenientes, Alonso Ruiz y Beltrán del Salto, y refrendadas por el canciller Francisco Díaz en el que expresa que este tipo de carta es "sin derechos". 


\subsubsection{Libro onzeno}

No hemos encontrado rastro de este undécimo libro. El Libro Manual lo describe así:

El qual es de mundanças por que en él non se asientan otras cosas salvo las asentadas en los dichos libros de la cámara que su alteza las manda mudar de una cosa en otra en la qual non han de permanesçer en la una ni en la otra y estas se asientan en este libro de qualquier condiçión que sean fasta que paran en cosa que non se ayan de mudar o fasta salir de la cámara e así es libro que ha de dar cuenta de la perla o piedra que se quitó de un joyel e se puso en otra cosa pero non para que se entienda que en él ay ninguna cosa cargada ni descargada salvo para hallar cada cosa donde está.

\subsection{Libro de mandatos de la reina ${ }^{77}$}

Este libro tiene encuadernación de cartera en pergamino, con cierto deterioro en la cubierta por bibliófagos. Tiene dos botones con sus ojales de piel blanca como cierre, unas dimensiones de 330 x 240 mm. y 218 folios.

En este libro hallamos distintos "mandatos" o "nóminas" de la reina, todos con un mismo formato poco más o menos. En realidad, son cédulas reales en las que la reina manda a Sancho de Paredes que entregue a la persona en cuestión una serie de cosas que se enumeran. Tras la enumeración de todos los objetos la reina manda al camarero que cuando sean entregados al destinatario, se le pida un recibo o "conosçimiento" de haberlos tomado; asimismo manda a los escribanos de la cámara que descarguen al camarero en el libro

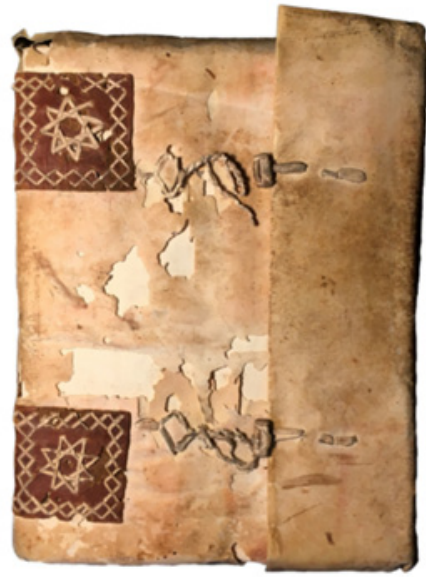
de cuentas o inventario los objetos enumerados. Cada nómina viene firmada por la reina y el refrendo del secretario (unas veces es Gaspar de Grizio, otras Miguel Pérez de Almazán). A continuación, viene el "conosçimiento" y firma del personaje que recibe los objetos, generalmente en el vuelto del folio, y la validación de uno o varios escribanos de la cámara dando fe que se ha hecho correctamente la entrega de las cosas enumeradas.

\footnotetext{
7 TPGB, CA. 68/012-B. Ortí Belmonte menciona un libro de "mandatos de la Reina, en donde figuran las entregas a sus hijas Isabel y María, reinas de Portugal, y a Catalina, de Inglaterra, de las alhajas y ropas del ajuar cuando se casaron". Op. cit., p. 266.
} 
Varios de los mandatos fueron destinados a sus hijas como dote o regalo de bodas, la infanta María, que fue reina de Portugal al casarse en 1500 con Manuel I el Afortunado (el rey viudo de su hermana mayor Isabel), y la infanta Catalina, princesa de Gales al contraer matrimonio en 1502 con el príncipe Arturo Tudor; asimismo fue beneficiada su sobrina Juana de Aragón, hija de la hermana pequeña de Fernando el Católico, que casó en 1502 con el rey Fernando II de Nápoles.

Aunque los folios están numerados, parece que fueron descolocados al encuadernar los mandatos cronológicamente y que falta algún cuaderno:

1. [ff. 1-7] A Juan de Calatayud le entregue una serie de objetos. Firmado en Madrid el 26 de mayo de 1499 por la reina Isabel y su secretario Gaspar de Grizio y señalado por el tesorero Morales. En las espaldas el recibo de conosçimiento.

2. [ff. 13-58] A Aldonça Suárez, camarera de la reina de Portugal, le entregue las "joyas de piedras e perlas e oro e plata e sedas e brocados, así en ropas como en pieças e cosas de camas, así de ropa blanca como de las otras cosas de vestir e de serviçio de la mesa e guarniçiones de angarillas e otras cosas, así de mulas como de andas". Firmado en Granada el 06 de octubre de 1500. Firmado por Isabel y su secretario Gaspar de Grizio y a las espaldas el conosçimiento de dicha camarera y Suero de Cangas y Diego Ramírez, escribanos de la reina Isabel, y Francisco de Hermosilla, escribano de la reina de Portugal, dando fe que se ha hecho la entrega de todos los objetos declarados en la lista.

3. [ff. 62-67] A Juan Ortiz, montero, para llevar a la reina de Portugal, su hija, o se las entregue a Aldonza Suárez su camarera, firmado en Granada el 27 de noviembre de 1500. Firman la reina y Gaspar de Grizio, con validación de Diego Ramírez y conoçimiento de Juan Ortiz de la recepción de los objetos.

4. [ff. 77-136] A Juan de Cuero, camarero de la princesa de Gales, firmado en Granada el 31 de mayo de $1501^{78}$.

5. [ff. 171-175] A Juana Urueña, condesa de Cortona, para la reina de Nápoles, firmado en Granada el 02 de junio de 1501.

6. [ff. 178-179] A la misma condesa de Cortona, para la reina de Nápoles, firmado en Granada en la misma fecha.

7. [ff. 187-188] A María, condesa de Montoro, firmado en la misma fecha.

8. [fol. 190] A María de Medina, criada de la reina Isabel, firmado en Granada el 03 de junio de 1501.

9. [ff. 186] Para entregar varas de brocado y seda a distintas personas, en la misma fecha.

10. [ff. 143-145] A Juan Ortiz para que las lleve a la serenísima princesa de Gales, en Granada a 28 de junio de 1501.

78 Documento 4. 
11. [ff. 195-203] A Ponçe Porçel, alcaide de las casas reales de la Alhambra "para que las tenga en guarda para hazer dellas lo que su alteza mande", firmado en Granada a 21 de octubre de 1501.

12. [ff. 71-72] A Pedro Navarro, repostero de camas de la reina de Portugal, su hija, para que se las lleve. En Granada a 28 de octubre de 1501.

13. [ff. 208-218] Tres mandatos a Theresa Enríquez, mujer del comendador mayor de León, para que le entreguen ciertas piezas de brocados e sedas e de oro tirado" "para hazer çiertos hornamentos e cosas de yglesias". Firmados el primero en Toledo el 19 de mayo de 1502 y los otros dos en la misma ciudad el 26 de agosto de 1502.

\subsection{Libro de la testamentaría de la reina ${ }^{79}$}

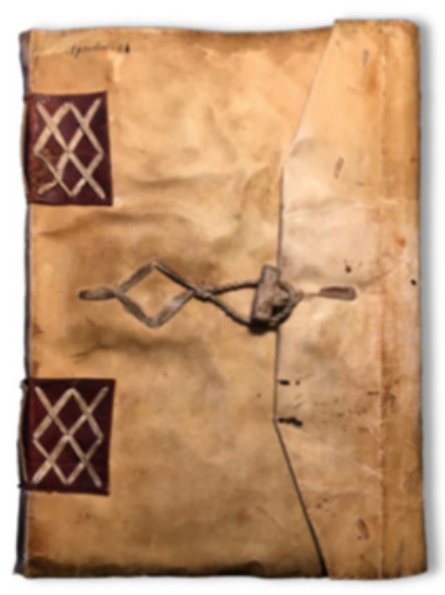

Tiene encuadernación de cartera en pergamino, con cierre de botón y ojal de piel blanca. Las medidas de este libro son de 330 x $240 \mathrm{~mm}$. y 161 folios.

Este libro contiene los recibos o cartas de pago que justifican la devolución de los objetos de la cámara de la reina que fue haciendo Sancho de Paredes, en distintas jornadas, al contador mayor de cuentas Juan Velázquez, para cumplir las mandas testamentarias de Isabel I.

La soberana había establecido en su testamento que se entregaran a Juan Velázquez todas sus pertenencias para venderlas y con lo obtenido "conplir e pagar las deudas e cargas e otras cosas". Tras su muerte el 26 de noviembre de 1504, el rey Fernando, con el deseo de llevar a término la última voluntad de su esposa, dirigió una cédula real al camarero Sancho de Paredes y su mujer Isabel Cuello el 30 de diciembre para que se cumpliera:

Por ende yo vos mando que luego entreguedes realmente y con efeto al dicho Juan Velázquez o a quien su poder oviere todas las ropas e hornamentos e joyas e piedras e perlas e oro e plata e camas de tapiçería e sedas e brocados e paños e ropa blanca e todas las otras cosas de qualquier valor e calidad que sean que están en vuestro poder, que son a vuestro cargo, que en qualquier manera pertenezcan a la dicha señora reyna, que aya santa gloria, ansi mismo

\footnotetext{
79 TPGB, CA. 68/012-A. Así describe Ortí Belmonte este libro: "la Testamentaría de la Reina, en donde el Camarero y su mujer entregan a Juan Velázquez, contador mayor de la reina $\mathrm{D}^{\mathrm{a}}$ Juana, como testamentario de la Reina, las alhajas de oro, plata, dinero y otras cosas, para que con ello se pague y cumpla el testamento de la Reina, fechado en Toro el 30 de diciembre de 1515". Op. cit., p. 266.
} 
entregad al dicho Juan López de Leçárraga todos los dineros e moneda de oro e plata que están en vuestro poder e a vuestro cargo, pertenesçiente a la dicha señora reyna o a quien su poder oviere e tomad cartas de pago de los dichos Juan Velázquez e Juan López o de quien su poder oviere de cada uno de ellos de lo que así les dierdes o entregardes...

Estas entregas, realizadas en distintas fechas y lugares, quedaron reflejadas en las ocho cartas de pago que entregó el contador al camarero, hechas ante la atenta mirada del escribano de las cámaras, que dio fe con su firma en todas las cartas de pago.

Son todas muy similares en la forma. Comienza siempre la carta con la intitulación del contador mayor con la fórmula "Conozco yo", con su nombre, apellido y cargos, que se dirige al camarero, para comunicarle que de él ha recibido una serie de piezas de las que va a hacer relación siguiendo el mandato del rey Fernando en una cédula real, que se copia literalmente:

Conozco yo Juan Velázquez contador mayor de la reyna doña Juana nuestra señora e del su Consejo que reçebí de vos, Sancho de Paredes, camarero de la reyna nuestra señora que aya santa gloria todas las cosas de plata e otras cosas que de yuso serán declaradas, las quales vos entregastes por virtud de una çédula firmada del rey nuestro señor e señalada de los testamentarios de su alteza. El thenor de la qual de verbo ad verbun es este que se sygue:

Después de la cédula real firmada por el rey que se reproduce literalmente, señalada por todos los testamentarios de la reina Isabel y con el refrendo del secretario Gaspar de Grizio, ${ }^{80}$ se le suma una validación de la cédula hecha por el mismo secretario:

Yo, Gaspar de Grizio, secretario de la reyna doña Ysabel que aya santa gloria doy fe por la presente que al tiempo que su alteza otorgó ante mí su testamento e postrimera voluntad dexó por sus testamentarios el señor rey don Fernando, su marido, e los reverendísimos señores don Françisco Ximénez de Çisneros arçobispo de Toledo, su confesor e del su consejo, e don fray Diego Deça, arçobispo de Sevilla que a la sazón era obispo de Palençia, confesor del dicho señor rey e del su consejo, e Antonio de Fonseca su contador mayor e Juan Velázquez su contador mayor, que entonçes

\footnotetext{
80 Por cuestión de espacio, vamos a omitir el texto de la cédula, que podemos encontrar editada en Torre y del Cerro, Testamentaría de Isabel la Católica, p. 1-2. Ruiz García, Los libros de Isabel la Católica: arqueología de un patrimonio escrito, pp. 318-319. Es de reseñar que por error del escribano se fechó la cédula el 30 de diciembre de 1505 en vez de 1504, y así se ha ido reproduciendo en multitud de lugares.
} 
era de la señora prinçesa doña Juana, ambos del su consejo, e Juan López de Laçarraga su secretario e les dio poer el dicho su testamento su entero poder e facultad para entrar e tomar todos sus bienes muebles doquier que los puediesen hallar e los vender e gastar e distribuyr para conplir e pagar las cosas en su testamento contenidas segund más largamente en el dicho su testamento se contiene, e asimismo doy fe como la clausula que en esta çédula de su alteza de esta otra parte escrita va ynxerta es la misma de verbo ad verbum que la dicha reyna doña Ysabel por el dicho su testamento ante mí otorgó, la qual yo saqué del dicho testamento para la yncorporar e poner en esta dicha çédula. Gaspar de Grizio.

A continuación, viene la enumeración de los objetos que Sancho de Paredes entrega a Juan Velázquez, con la idéntica descripción que venía en los libros de la cámara, con su peso y tasación si era una joya o una pieza de material noble; concluye la relación de las cosas entregadas, indicándose la cantidad de folios que tiene la carta de pago, tras lo cual se plasma el contador mayor da su conformidad con la data completa y su firma autógrafa:

Las quales dichas cosas de plata e otras cosas según e de la forma e manera que en estas veynte e dos hojas de pliego entero van escritas e espeçificadas, yo el dicho Juan Velázquez, contador mayor, las reçibí realmente e me dy por contento e entregado de ellas, de vos el dicho Sancho de Paredes, camarero de la reyna nuestra señora que aya santa gloria e porque es verdad lo firmé de mi nombre, fecho en la çibdad de Toro a XXIII días del mes de abril de mill e quinientos e çinco años. Juan Velázquez [rúbrica].

Seguidamente vienen las palabras de un Contador Mayor de Cuentas:

Pasado en quenta al dicho Sancho de Paredes todo lo contenido en esta carta de pago fasta aquí [señal de Alonso Ruyz, teniente de contador mayor de cuentas]

Y, por último, la validación del escribano de las cámaras, Suero de Cangas:

Yo Suero de Cangas, escribano de la cámara de la reyna nuestra señora que aya santa gloria que todas las cosas contenidas en este cuaderno resçibió en mi presençia en nombre del señor Juan Velázquez, Baltasar de San Román su criado según e de la manera que en este dicho quaderno va declarado con los trece botones que van en la margen señalados de mi señal, en fe de lo qual firmé aquí mi nombre, fecha en la çibdad de Toro a veynte e ocho días de abril de mill e quinientos e çinco años. Suero [rúbrica]. 
Ocho son las cartas de pago que encontramos en este libro ${ }^{81}$, a saber:

1. La primera es de "cosas de plata e otras cosas" tiene 22 folios y está firmada por Juan Velázquez en Toro el 23 de abril 1505.

2. Esta carta es "de cosas de ornamentos e doseles e sitiales e almohadas e tapiçería e cosas de camas", tiene 12 folios y está firmada en Arévalo 14 de mayo de 1505.

3. Esta carta tiene 37 folios y está firmada en Arévalo a 10 de junio 1505.

4. Esta tiene 50 folios y se firma el 10 de junio 1505 en Arévalo.

5. Otra con 5 folios del 10 de junio 1505 en Arévalo.

6. Otra más de 34 folios con la misma data.

7. Una carta de 9 folios firmada en Arévalo el 15 de julio 1505.

8. Por último, otra de 3 folios firmada en Segovia el 12 octubre 1505.

Como podemos apreciar, fueron los días de junio los de mayor trabajo, en los que recibieron en nombre del contador mayor varios de sus criados, como queda reflejado en una de las cartas de ese día, donde también firmaron los criados de Juan Velázquez -Juan Saravia, Baltasar de San Román y Juan Gutiérrez-:

Pedro Saravya, moço después que fue de su Alteza e Juan Gutiérrez montero que asy mismo fue de su alteza, de las quales la primera hoja está señalada del dicho Baltasar de San Román e las otras treinta e un del dicho Pedro Saravya e la otra del dicho Juan Gutiérrez e Pedro Saravya, lo qual todo ellos reçibieron según e de la forma e manera que en estas dichas treinta e tres hojas va escrito e declarado en fe de lo qual firmé aquí mi nombre. Fecha en la villa de Arévalo a diez días del mes de junyo de mile e quinientos e tres años ${ }^{82}$.

En el AGS encontramos la cuenta que quedó en poder de Juan Velázquez para la posterior gestión de la venta en almoneda de los bienes de la reina en el legajo AGS, CMC, 1EP, LEG. 81.

\footnotetext{
81 En el Archivo Histórico Nacional se encuentra otra carta de pago más antigua que las encuadernadas en este legajo. Está fechada en Toro el 10 de marzo de 1505 en AHN,DIVERSOS-COLECCIONES,290,172.

82 Evidentemente se confundió, no es 1503 sino 1505.
} 


\subsection{Libro del finiquito de su cargo de camareros3}

Tiene encuadernación en cartera con cuero y estampaciones con pan de oro; tuvo un cinto que ha perdido. Las medidas de alto, ancho y grosor son de $410 \times 280 \times 140 \mathrm{~mm}$. Tiene 580 folios, de los cuales, los primeros 556 están numerados, los siguientes 15 están sin numerar y 9 más en blanco). Es el más grande y voluminoso de todos los ejemplares.

En este libro se reúnen tres cuentas de cosas de la cámara que los camareros rindieron ante los contadores mayores de cuentas en distintas fechas, con sus correspondientes cartas de finiquito:

1. ff. 1-276. Dada la carta de finiquito en Segovia el 20 de octubre de 1503.

2. ff. 277-296. Firmada la carta de finiquito en Medina del Campo el 26 de enero de

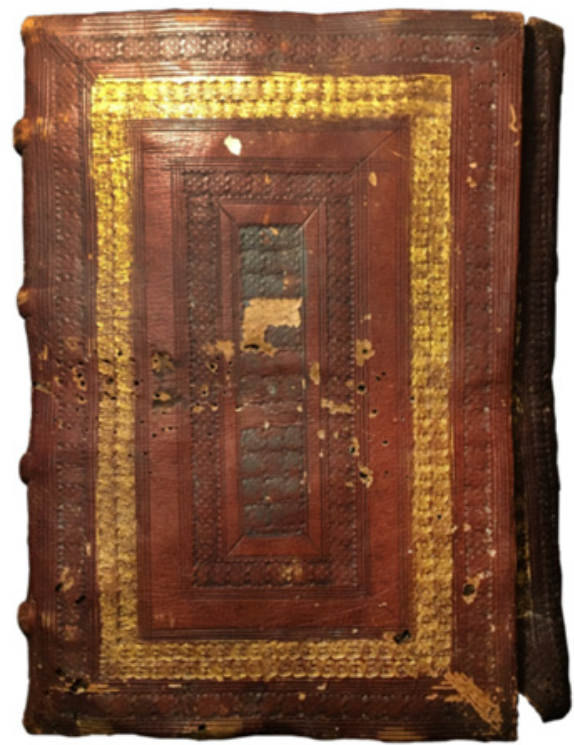
1504.

3. ff. 297-556 [+15 últimos folios sin numerar] Esta última es la cuenta que rindieron los camareros ante Juan Velázquez, tras la muerte de la reina Isabel.

Bien sabían Sancho de Paredes e Isabel Cuello que, en el momento en que cesaran en su oficio, tendrían que rendir cuenta, con los libros en la mano, de todos los objetos de la cámara de la reina a ellos confiados para devolverlos ${ }^{84}$. Era misión de la Contaduría Mayor de Cuentas llevar a cabo esta labor de fiscalización, pues su función era procurar que no se cometieran fraudes en el manejo de los bienes públicos, tanto del erario como de las propiedades reales.

Como hemos visto, a la muerte de Isabel, el rey Fernando mandó a través de una real cédula a Sancho de Paredes e Isabel Cuello que entregasen a Juan Velázquez, contador mayor y testamentario, todo lo que tenían a su cargo de la reina, tras lo cual y con el debido juramento de no quedar nada por traspasar, recibirían la carta de finiquito.

Encontramos la constancia documental de todos los pasos de esta acción administrativa en el Archivo General de Simancas, concretamente en el legajo CMC, 1EP, LEG. 186,

\footnotetext{
83 TPGB, CA. 68/011. Ortí Belmonte habló de este libro como el "finiquito de su cargo de Camarero, y en donde hay dos cartas de Sancho de Paredes e Isabel Cuello de lo que en su poder quedó en la cámara de la Reina a su fallecimiento para hacer entrega a doña Juana".

${ }^{84}$ Para la gestión administrativa de los bienes muebles de la reina cf. RuIZ GARCİA, Los libros de Isabel la Católica: arqueología de un patrimonio escrito, pp. 30-34 y MARTíN BARBA, "El desarrollo de la almoneda de los bienes muebles de Isabel la Católica”, pp 250-263.
} 
en el palacio de los Golfines de Abajo, en este Libro del fin y quito, y otros documentos en el Archivo Histórico Nacional.

El legajo simanquino lleva en la cubierta el título "Libro de los cargos de la Cámara de la reyna nuestra señora, que aya santa gloria, dados por Sancho de Paredes e Ysabel Cuello que a su cargo tenían. Año de DV" y el primero de sus pliegos está encabezado por un título que lo describe de forma parecida: "De la cuenta que se tomó al camarero Sancho de Paredes y a Ysabel Cuello su muger camareros que fueron de la reyna doña Ysabel, muy sancta gloria, de todas las cosas que tenya de la cámara a su cargo. Cuentas duplicadas". Efectivamente, en este legajo encontramos copia por duplicado de las cédulas reales que Fernando, como gobernador y administrador del reino a la muerte de su esposa, envió a Sancho de Paredes e Isabel Cuello ordenándoles la entrega de los objetos de la cámara de la reina; asimismo, los juramentos respectivos de ambos declarando haber entregado todos los bienes y no haberse quedado con nada, rubricados con sus firmas autógrafas; además el registro, también por duplicado, de todos los objetos entregados al contador mayor y sus oficiales; y por último, la copia de la carta de fin y quito que la Contaduría Mayor de Cuentas expidió en nombre de la reina Juana para los camareros. Esta documentación es la que se quedó esta institución para su archivo, y así quedó conservada hasta el día de hoy ${ }^{85}$.

En el Libro de fin y quito del Palacio de los Golfines de Abajo encontramos, en el tercero y último de los finiquitos, la carta original que la Contaduría Mayor de Cuentas extendió a Sancho de Paredes e Isabel Cuello en Salamanca el 5 de febrero de 1506. Está intitulada por la reina Juana y firmada por el contador mayor de cuentas, Rodrigo de Qualla, y su lugarteniente, el bachiller Alonso Ruiz. Lleva la validación del sello mayor de Corte de los Reyes Católicos, monofaz, circular y de $8 \mathrm{~cm}$., así como las firmas de Bartolomé Ruiz de Castañeda en cuanto canciller real y de Ruy Fernández de Alcoçer como escribano de cámara de la reina y de la Audiencia de la Contaduría Mayor de Cuentas ${ }^{86}$.

Pocos días antes, una vez concluida la fatigosa entrega de los camareros a Juan Velázquez de la multitud de objetos de todo tipo de las cámaras reales que tenían a su cargo, que se había prolongado más de un año desde la muerte de la reina ${ }^{87}$, los contadores mayores de cuentas revisaron todas las cuentas en los libros, cédulas y mandatos, comprobaron que se había efectuado la entrega correctamente y concluyeron con su aprobación el 30 de diciembre de 1505. A continuación, examinaron las cuentas del dinero que habían manejado en la cámara (176.485 maravedís) y firmaron su conformidad en la misma jornada.

Pero al repasar Sancho de Paredes sus libros de la cámara, comprobó que había una serie de objetos que habían desaparecido, bien por pérdida, bien por gasto, bien por hurto a lo largo de sus años como camarero, que él ya no tenía, y que no le habían

87 Si un año tardaron en traspasar todos los objetos de la cámara de la reina al contador Juan Velázquez, ocho años tardó este en concluir la venta de todos los objetos. Cf. MArTín BARBA, José Julio, “El desarrollo de la almoneda de los bienes muebles de Isabel la Católica”.
} 
sido descargados. En consecuencia, escribió una carta al rey haciéndole una relación de los objetos para que dispusiera el monarca como tenía que obrar, gesto que muestra su honradez y buen hacers8. La respuesta de Fernando, con el acuerdo de "los otros testamentarios de su señoría", fue una real cédula ordenando a los contadores mayores que les descargaran todas las cosas enumeradas, "considerando la fidelidad de los dichos Sancho de Paredes e Ysabel Cuello su muger" " ${ }^{9}$. Estas aparecen de nuevo en el alcançe final de la carta de finiquito, las cuales no se les tomó en cuenta.

Aprobadas las cuentas, los camareros tuvieron que hacer el juramento preceptivo ante escribano público de que nada de la reina quedaba en su poder. Isabel Cuello juró el 14 de enero de 1506 en Arévalo con cuatro testigos ${ }^{90}$, Sancho de Paredes unos días más tarde, en Cáceres el 27 de enero con tres testigos ${ }^{91}$. Por fin, el 5 de febrero recibieron la Carta de finiquito con la cual quedaban liberados de su responsabilidad para siempre ${ }^{92}$.

\section{Conclusión}

Fue voluntad de Isabel I nombrar tenientes de camarero a este joven matrimonio porque sus predecesores, los padres de ella, "estavan ya cansados". Ardua y laboriosa preveía la reina la labor de registro e inventario de todas sus pertenencias, para la cual pensó que nadie mejor que ellos podrían llevar a cabo esta tarea. Intuimos que los anteriores camareros, Martín y Beatriz Cuello, no habían hecho inventario o, por lo menos, no conocemos datos de su existencia. En el albalá de merced de ambos, se especifica que fueron nombrados para que "tenga cargo e le sean cargadas" las cosas de la cámara, tanto las que había en ese momento, como las que habían de llegar en el futuro "segund e por la forma e manera que el comendador Martín Cuello e su muger sus padres, mis camareros, lo han tenido e tienen fasta agora". Considero que es reveladora la distinción hecha entre "tenga cargo" y "le sean cargadas", pues "tener cargo" estaría haciendo referencia al oficio de camareros, de cuidar y encargarse de los objetos de la cámara como lo habían realizado los anteriores camareros, mientras que "le sean cargadas", estaría haciendo alusión a la realización de un inventario, que parece ser que no había anteriormente, y que la soberana quiso que acometieran Sancho de Paredes e Isabel Cuello.

Los escribanos de las cámaras documentaron y validaron la gestión administrativa del cargo y descargo a los camareros de los bienes muebles de la reina con la elaboración a mano de los libros de la cámara. Diego de Medina, escribano de las joyas de la cámara, con Francisco de Hermosilla y Diego Salinas comenzaron el trabajo de elaboración de los libros en abril de 1498 en la ciudad de Alcalá de Henares. Poco después, Diego Ramírez tomó las riendas, por mandato de la reina, aportando un criterio sistemático a la gestión. A las jornadas de cargo de las cosas de la cámara a Sancho de Paredes e Isabel Cuello

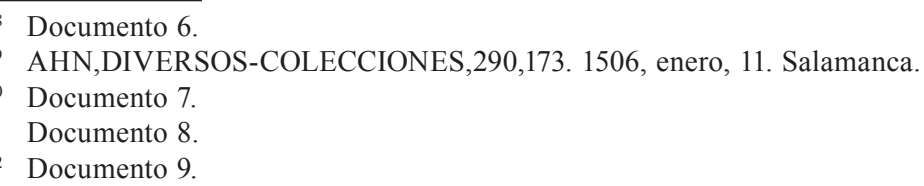


en la ciudad complutense se sucedieron otras jornadas en las ciudades de Toledo (abril 1498), Guadalajara (mayo 1498), Zaragoza (septiembre 1498), Ocaña (enero 1499), Madrid (marzo-mayo 1499), Sevilla (enero-junio 1500) y Granada (septiembre1500-septiembre 1502). A partir de la segunda mitad de 1502, fue Suero de Cangas, otro escribano de la cámara, el que firmó los cargos, sustituyendo a Diego Ramírez en la validación con firma: Toledo (abril-septiembre 1502), Madrid (noviembre-diciembre 1502), Alcalá de Henares (enero-julio 1503), Segovia (agosto-noviembre 1503), Medina del Campo (enero-diciembre 1504). Estos escribanos de la cámara autenticaron con las debidas garantías en los libros cada uno de los actos de cargo y descargo de todas las pertenencias de la cámara de la reina, por insignificantes que parecieran. Estos libros son la expresión de una documentación que dio a ambas partes, tanto a la reina como al camarero, todas las garantías legales. Por otra parte, la labor de intervención y control de la Contaduría Mayor de Cuentas en la gestión del camarero y de los escribanos hizo que sendas actividades se realizaran con mayor transparencia.

Poco después de la muerte de la reina Isabel I de Castilla, todos los objetos que se habían cargado desde 1498 a Sancho de Paredes e Isabel Cuello tenían su data correspondiente en los nueve Libros de cuentas de la cámara o inventario, es decir ya habían sido descargados, bien por orden de la reina Isabel en vida a través de cédula o mandato real, bien por cédula real del rey Fernando y los testamentarios de la reina tras su muerte; de este modo, los camareros recibieron el cinco de febrero de 1506 la carta del finiquito de todos los objetos de la cámara real.

La buena gestión administrativa de Sancho de Paredes y su esposa Isabel Cuello hizo que pudieran abandonar la Corte y marchar a Cáceres con sus cartas de finiquito y satisfechos de su trabajo minuciosamente bien realizado. Por ello recibieron de los monarcas multitud de beneficios y mercedes, gracias a los cuales pudieron construirse el magnífico palacio que hasta el día de hoy podemos contemplar en la ciudad de Cáceres, donde siguen intactos los libros que testimonian esta labor. 


\section{APÉNDICE DOCUMENTAL}

1498, marzo, 05. [Alcalá de Henares]

[Albalá de merced de Isabel I de Castilla a Isabel Cuello para que tenga cargo y le sean cargadas las cosas de su cámara]

TPGB, CA, 54/022.

AGS, CSR, LEG. 43-212, fol. 104r

[Margen superior centro:] Cruz

Yo la rreyna fago saber a vos, el mi mayordomo e contador mayores de la despensa e raçiones de mi casa, que mi merçed e voluntad es de reçibir en mi cámara a Ysabel Cuello mi criada para que tenga cargo e le sean cargadas ${ }^{93}$ las cosas de mi cámara o las que agora en ella ay e las que se entregaren de aquí adelante segund e por la forma e manera que el comendador Martín Cuello e su muger sus padres mis camareros lo han tenido e tienen fasta agora. E que aya e tenga de mi en cada un año para su vistuario quinze mill maravedís porque vos mando que lo pagades e asentedes así en los mis libros e nóminas de las raçiones e quitaçiones que vosotros tenedes e libredes a la dicha Ysabel Cuello los dichos quinze mill maravedís desde primo día del mes de enero deste presente año fasta en fin del dicho año e dende en adelante en cada un año segund e quando librardes a las otras mugeres de mi casa los semejantes maravedís que de mi tienen e asentad el treslado deste mi alvalá en los dichos mis libros e sobre escrevid e bolved esta original a la dicha Ysabel Cuello para que la tenga por título e rrazón de dicho su ofiçio e no fagades ende al. Fecha a çinco días del mes de março año del naçimiento de nuestro salvador Ihesuchristo de mile e quatroçientos e noventa e ocho años. Yo, la Reyna.

Yo, Gaspar de Grizio, secretario de la rreyna nuestra señora la fize escrevyr por su mandado.

[En el reverso:] Asentóse este alvalá de la reyna nuestra señora de esta otra parte escrito, en los sus libros de las raçiones que tyenen el comendador don Gonçalo Chacón mayordomo mayor de su alteza e don Gonçalo Chacón contador mayor de la dispensa e raçiones de su casa para que se haga e cunpla lo en ella contenido segund su alteza enbía mandar. Guevara - Juan de Torres.

93 Tachado: las 
1498, marzo, 12. [Alcalá de Henares]

[Cédula real de Isabel I de Castilla a Diego de Valladolid, despensero de mesa de la reina, para que de a Isabel Cuello 25.000 maravedís anuales para su ración y mantenimiento]

TPGB, CA, 54/043.

[Margen superior centro:] Cruz

La Reyna.

Diego de Valladolid, mi despensero de mesa, yo vos mando que deys en mi despensa a Ysabel Cuello mi criada para su raçión e mantenimiento veynte e çinco mill maravedís en cada un año los quales le dad en las cosas que ella quisiere de mantenimientos contando lo que oviere de aver cada día al respeto de los dichos veynte e çinco mill maravedís de manera que aya otra tanta raçión como tiene e le pagays en la dicha mi despensa a Beatriz Cuello su madre, asy en dineros como en mantenimientos como ella más quisiere, los quales le dad este presente año de la fecha desta fasta en fin del dicho año e dende en adelante en cada un año. E por esta mando al mi mayordomo e contador mayores de la dicha mi despensa e raçiones de mi casa que vos reçiban e pasen en cuenta los dichos veynte e çinco mill maravedís de la dicha raçión así este dicho año como los otros años venideros. Fecha a dose días de março de noventa e ocho años. Yo la Reyna.

Por mandado de la Reyna, Miguel Pérez d'Almaçán.

[En el margen inferior:] Para que den en la despensa a Ysabel Cuello otra tanta raçión como se a Beatriz Cuello su madre.

1498, marzo, 15. [Alcalá de Henares]

[Albalá de merced de Isabel I de Castilla a Sancho de Paredes para que sea teniente de camarero y le sean cargadas las cosas de su cámara]

TPGB, CA, 54/023.

AGS, CSR, LEG. 43-212, fol. 103r

[Margen superior centro:] Cruz

Yo la rreyna fago saber a vos el mi mayordomo e contador mayores de la despensa e raçiones de mi casa que mi merçed e voluntad es de reçibir por tiniente de camarero por donna Ynés Manrrique mi camarera mayor e para que le sean cargadas las cosas de mi cámara a Sancho de Paredes e que aya e tenga de mí de quitaçión en cada un año treynta mill mrs. e porque vos mando que lo pongades e asentedes asy en los mis libros e nóminas de las raçiones que vos otros tenedes e libredes al dicho Sancho de Paredes los dichos 
treynta mill maravedís desde primero día del mes de enero deste presente año de la fecha deste mi alvalá e dende en adelante en cada un año segund e quando librardes a las otras personas de mi casa a los semejantes maravedís de mi tienen e asentad el traslado deste mi alvala en los dichos mis libros e nóminas e dadle este original al dicho Sancho de Paredes sobreescrito e librad de vos otros para que lo él tenga. E es mi merçed e voluntad que aya e gose e le sean guardadas todas las onrras, graçias, merçedes, franquesas e libertades e estaçiones que por rrazón de lo susodicho deve aser e gozar e le deve ser guardadas e no fagades ende al. Fecho a quinze días del mes de março año del nasçimiento de nuestro señor Iesuchristo de mill e quatroçientos e noventa e ocho años.

Yo la reyna.

Yo Gaspar de Grizio, secretario de la rreyna nuestra señora la fize escrevyr por su mandado.

[En el margen inferior:] Q.V.A. reçibe por tiniente de camarero por doña Ynés Manrrique su camarera mayor e por uq ele sean entregadas las cosas de la cámara a Sancho de Paredes con rraçión de xxxU cada año.

1501, mayo, 27. Granada

[Mandato de Isabel I de Castilla a Sancho de Paredes para que dé a Juan de Cuero una serie de objetos para entregar a la infanta Catalina, princesa de Gales, dentro del Libro de mandatos]

TPGB, CA.68/012-B, ff. 77-86.

// lxxvii [Margen superior centro:] Cruz

[Debajo:] La Reina

Sancho de Paredes, mi camarero, yo vos mando que de las cosas que deys e entreguéys luego a Juan de Cuero camarero de la Serenísima princesa de Galez mi muy cara e muy amada hija todas las joyas de oro con piedras e perlas e sin ellas, e toda la plata dorada e blanca e tapaçería e hornamentos e vestidos e doseles e señales e cortinas e almohadas de brocados e sedas e ropa blanca e alhombras e guarniçiones de mulas e trotones e atavios de camas e todas las otras cosas que en esta mi nomina van declaradas e en ella se contienen en esta manera:

Primeramente le dad y entregad una cruz de plata dorada labrada la cruz y el pie de synzel e maginería que es la dicha cruz fecha de unos rrotulos tallados de unos follajes de buril y por los braços unas adormideras que tiene diez engastes redondos y en cada uno un ángel que tiene en las manos los martiros de la pasión esmaltados de azul e verde e morado con un cruçifixo encarnado, que pesó todo junto treynta e

libro III, cartas XV

1 cruz

XXXI marcos, III onças, VI ochavas 
un marcos e tres onças e seys ochavas la cruz y el pie, con su caxa de cuero y la cruz envuelto en un paño de lienço de nabal.

\section{[a continuación sigue la enumeración de todos los objetos a lo largo de 58 ff.]}

// lxxxvi Las quales dichas joyas de oro con piedras e perlas e sin ellas e plata dorada e blanca e tapaçería e alhonbras e hornamentos e vestidos e doseles e sytiales e almohadas e cortinas de brocados e sedas e ropa blanca e atavios de camas e guarniçiones de trotones e mulas con todas las otras cosas que en esta mi nomina van declaradas e en ella se contienen, vos mando que las deys e entreguéys luego al dicho Juan de Cuero para que él las lleve e tenga en guarda para el serviçio de la dicha serenísima prinçesa e tomad su carta de conosçimiento de como resçibe de vos todas las cosas susodichas que en esta dicha mi nómina van declaradas e se contiene con la qual e con esta dicha mi nómina vos doy por libre e quito de todo ello e de cada una cosa e parte dello e mando a los escrivanos de mi cámara que vos las descargue de los libros del cargo donde vos las tienen cargadas. Fecha en la çibdad de Granada a treynta y un días del mes de mayo de mill e quinientos e un años.

Yo la reina [rúbrica]

Por mandado de la reyna. Miguel Péres de Almaçán [rúbrica].

// lxxxvi verso Yo Juan de Cuero camarero de la muy alta e muy esclaresçida prinçesa de Gales mi señora, conozco que resçibí de vos Sancho de Paredes, camarero de la reyna nuestra señora todas las joyas de oro con piedras e perlas e toda la plata dorada e balnca e ropa blanca e ropas de bestyr de brocados y sedas y hornamentos e sytiales e doseles e almohadas de brocados e sedas e brocados en pieças e tapeçería e alhombras y goarniçiones e todas las otras cosas que en esta nomina de su alteza van nombradas e declaradas que va escripta en çinquenta e seys hojas de pliego entero de la marca menor las quales dichas joyas de oro con piedras e perlas e plata dorada o blanca e todas las otras cosas que en esta dicha nómina de su alteza van contenidas e declaradas que vos me distes e entregastes e yo de vos reçiby por mandado de su alteza para las tener en guarda e servyr con ellas a la dicha señora prinçesa, las quales vos me distes e entregastes en presençia de Suero de Cangas e Diego de Salinas e Diego Ramyres escrivanos de la cámara de la rreyna nuestra señora e de Françisco de Nurueña escrivano de la cámara de la serenísyma prinçesa mi señora e por que es verdad vos dí este conosçimiento firmado de mi nombre. Fecho en la çiudad de Granada e veynte e syete días del mes de mayo de mill e quinientos e un años.

Juan de Cuero [rúbrica].

Yo Suero de Cangas e Diego Ramírez e Diego de Salinas escrivanos de la cámara de la reyna nuestra señor a Françisco de Noreña escrivano de la cámara de la prinçesa de Gales mi señora damos fee como el dicho Sancho de Paredes dio e entregó al dicho Juan de Cuero todas las joyas de oro e perlas e piedras e plata e ropas de vestir e ornamentos e doseles e sytiales e almohadas de brocados e sedas e brocados en pieças e tapeçería e 
alhonbras e ropa blanca e todas las otras cosas que en esta nómina de la reyna nuestra señora van declaradas e en ella se contienen, para que el dicho Juan de Cuero las lleve e tenga para servicio de la dicha señora prinçesa. En fee de lo qual nos las sobredichas firmamos aquí nuestros nombres. Fecho en la çibdad de Granada veynte e syete días de mayo de mill e quinientos e un años.

Diego Ramírez [rúbrica]. Suero de Cangas [rúbrica]. Diego de Salinas [rúbrica]. Francisco de Noreña [rúbrica].

1505, diciembre, 30. Salamanca

[Finiquito de la Contaduría Mayor de Cuentas a Sancho de Paredes de unos dineros que tuvo a su cargo mientras fue camarero de la reina Isabel I de Castilla]

TPGB, Libro Deseno.

[Margen superior centro:] Cruz

Don Fernando e don Felipe e doña Juana, por la graçia de Dios, reyes e prínçipes de Castilla, de León, de Aragón, de las dos Seçilias, de Jerusalén, de Granada e archiduqes de Austria, duques de Borgoña etc. Por quanto vos Sancho de Paredes, camarero de la señora reyna doña Ysabel que aya santa gloria, reçibistes por su mandado çiertas quantías de maravedís para tener en su cámara a faser dello lo que vos fuese mandado e por nuestro contadores mayores de cuentas vos fue pedido que les diesedes cuenta e razón e que declarasedes ante ellos las quantías de maravedís que avíades reçebido e de qué personas e en qué manera e vos paresçistes ante ellos a les dar e distes la dicha cuenta e mostrastes ante ellos vuestro libro de cuentas en el qual estava sentado todo el cargo e data de maravedís de la dicha vuestra cuenta por virtud de la qual e del juramento que sobre ello fezistes, se vos fiso el cargo e demás e allende desto nostrastes por çédulas e mandamientos todas las quantías de maravedís que vos fueron reçibidas en cuenta para vuestro descargo en carta de pago de las personas que lo ovieron de aver según que por ystenso queda asentado en los libros de las nuestras cuentas e según que adelante en esta carta de finiquito dirá en esta guisa:

[En el centro]: Cargo

Así que montan todos los maravedís que vos el dicho Sancho de Paredes, camarero de la dicha señora reyna, recibistes e se vos faze cargo çiento e setenta e seys mil e quinietos e ochenta e çinco maravedís, de los quales, descontados los dichos çiento e sesenta e dos mile e dosientos e sesenta e ocho maravedís que aveys dado e pagado en la manera que dicho es, paresçe que quedays deviendo catorze mill e dosientos e diez e siete maravedís, con que aveys de acudir a Bartolomé de Çuloaga, thesorero de los dichos cargos. 
Agora por vos el dicho Sancho de Paredes, camarero que fuistes de la serenísima reyna doña Ysabel mi señora madre que aya santa gloria, me fue suplicado e pedido por merçed que pues vos avíades dado la dicha cuenta a los dichos mis contadores mayores de cuentas e por ella paresçía non me quedar deviendo más de catorsemill e dosientos e diez e siete maravedís, del dicho alcançe que a mi merçed pluguiese de vos mandar dar mi carta de finiquito de todos los maravedís que montó el dicho vuestro cargo e como la mi merçed fuese e por quanto ante los dichos mis contadores mayores de cuentas fesistes juramento en forma de derecho que en la dicha vuestra cuenta así el cargo como en la data es buena e çierte e que en ella ni en parte della no ovo ni ay fraude ni encubyerta alguna, tovelo por bien por ende yo la dicha reyna doña Juana por esta mi carta de finiquito lo o e apruevo la dicha cuenta e la he por buena e çierta e verdadera e vos doy por libre e quito a vos e vuestros bienes e a vuestros herederos e subçesores e aquel o aquellos que de vos o de ellos ovieren título o cabsas a este fin e quito se contiene eçebto de los dichos catorze mill e dozientos e diez e siete maravedís que me quedays deviendo por quanto por la dicha cuenta paresçe aver dado e pagado realmente e con hefetto todos los maravedís que monta en la dicha data porque dello mostrastes escrituras e recabdos bastantes por donde dichos vuestros bienes ni herederos no me queda ni finca a mí ni a los reyes que después de mí vinieren abción ni otro recurso alguno por razón de los dichos maravedís que en este dicho finiquito se vos hiso cargo çerto a los dicho catorzemile e dosientos e diez e siete maravedís que dedan que me aveys de dar e pagar de dicho alcançe según dicho es e mando a los dichos mis contadores mayores de cuentas que agora so o será que vos non llamente a vos ni a los dichos vuestros herederos para que les ayades de dar otra vez cuenta deste dicho cargo pues ya la aveys dado así vos llamaren. Quiero y es mi voluntad que no seays obligado vos ni ellos a venir ni enbiar ante ellos a sus llamamientos en enplasamientos e por los así hazer non yncurráys en pena alguna e atrosy mando a las mis justicias así de la mi casa e corte e chançiller como de todas las que vos la guarden e cumplan e fagan guardar e complir en todo según que en ella se contiene, so pena de la mi merçed e de diez mill maravedís para la mi cámara e desto vos mandé dar esta mi carta sella e librada de los dichos mis qontadores mayores de cuenta e de sus lugares tenientes, dada en la çibdad de Salamanca a treynta días del mes de diziembre del nasçimiento de nuestro señor Ihesuchristo de mill e quinientos e seys años ${ }^{94}$.

[Sello de placa de la poridad con cera roja] Rodericus de Qoalla licenciatus - Alonso Ruyz [rúbrica] - Rodrigo de Alcoçer [rúbrica] Castañeda chançiller [rúbrica].

\footnotetext{
94 Tachado enero y sobreescrito diciembre. Es imposible que este finiquito fuera firmado el 30 de diciembre de 1506, la data ha de ser indudablemente el 30 de diciembre de 1505, pues en 1506 Felipe ya había muerto y Fernando se hallaba en Nápoles, y ambos intitulan junto con Juana la carta de finiquito... Seguramente el escribano después de escribir treinta de enero de 1506 quiso retrotraer la fecha a diciembre sin darse cuenta de que también tenía que haber corregido el año. Efectivamente, el treinta de diciembre de 1505 es cuando se firmó el finiquito de las cosas de la cámara, aunque luego hubo que prolongarlo hasta febrero de 1506 , como podemos leer en el final del Documento 8.
} 
1506, s.d. Salamanca

[Carta de Sancho de Paredes al rey Fernando con un memorial de las cosas que tenía a su cargo que no entregó por haberse gastado o perdido y que no le descargaron de los libros de cuentas]

AHN, DIVERSOS-COLECCIONES,288,63.

[Margen superior centro:] Cruz

Muy alto y muy poderoso señor

Sancho de Paredes, camarero de la reyna nuestra que aya santa gloria, besa las reales manos de vuestra alteza, a la qual plega saber como él ya a entregado a Juan Velázquez todas las cosas que él tenía a su cargo de la cámara de su alteza y agora, conçertando los cargos que él halla por sus libros que le están hechos con los descargos de lo que se ha entregado e vendido, paresçen algunas cosas que le demandan los libros que él no tiene, y porque se han gastado y no descargado y porque puede ser averse perdido o hurtado, que en tan gran cosa como ha sido en su tiempo la cámara de su alteza, así en las cosas que ha resçibido como en las que ha dado todo junto como se hizo en Granada y en otras partes, no es de maravillar. Y asimismo, otras que le alcançan que debe y otras que él tiene sin cargo ninguno dellas porque su alteza las dava por determinar que avían de quedar en la cámara y otras por alguna ynadvertençia las quales haze saber a vuestra alteza, para que en todo mande hazer lo que más fuere su serviçio, que son las siguientes; pero no viene aquí algunos dineros que se hizieron de lo que se vendió a más de lo tasado, hasta se averiguar la cuenta de lo vendido con lo entregado, lo qual, para entonçes, lo enviaré asimismo a vuestra alteza y comoquiera que es notorio que yo no tuve de su alteza ofiçio de confiança sino de cuenta y con oficiales y la tengo jurada y la he de jurar ante contadores de cuentas, yo juro por Dios a vuestra alteza que todo lo que aquí va es verdad y que yo no soy en cargo de otra cosa que yo al presente sepa, y así lo han jurado los que tenían las otras cosas que yo y mi mujer guardávamos. Las cosas que no [a]parecen e están cargadas en los libros:

(Se hace una relación de cosas a lo largo de tres folios)

1506, enero, 14. Arévalo

[Juramento de Isabel Cuello ante escribano público de que entregó todas las pertenencias de la reina Isabel y no se quedó con nada]

AGS, CMC,1EP, LEG,186, s.f.

[Arriba centro:] (Cruz). 
[Al margen izquierdo:] Juramento de Ysabel Cuello, muger del camarero Sancho de Paredes.

En la villa de Arévalo, a catorze días del mes de henero, año del nasçimiento de nuestro Saluador Ihesuchristo de mill e quinientos e seys años, ante el bachiller Beltrán, alcalde en la dicha villa por sus altezas e en presençia de mí, Sancho Rodríguez, escrivano público en la dicha villa de Arévalo a la merçed de sus altezas, e testigos yuso escriptos, paresçió presente Sancho Blego, criado de Sancho de Paredes, camarero que fue de la reyna, nuestra señora, que Santa Gloria aya, en nonbre de Ysabel Cuello, muger del dicho Sancho de Paredes, e dixo que, por quanto la dicha Ysabel Cuello, para cosas que le convienen, ha de hazer una solenidad de juramento por ante escrivano público para lo enbiar sygnado ante sus altezas e ante los sus contadores mayores de cuentas, y porque el dicho Sancho de Paredes al presente no es en esta dicha villa para que él le diese liçençia para hazer la dicha solenidad e juramento, por su ausençia pidió al dicho señor alcalde él le diese e mandase dar la dicha liçençia para hazer el dicho juramento, y porque conste al dicho alcalde del ausençia del dicho Sancho de Paredes, marido de la dicha Ysabel Cuello, hizo presentaçión de testigos, que luego presentó a Christóval de Torres, alguasil de la dicha villa, e a Juan Arias, procurador de cabsas, los quales estavan presentes, de los quales el dicho alcalde resçibió solenidad e juramento en forma devida de derecho e, asý fecho, luego el dicho alcalde les preguntó, so cargo del juramento, sy sabían quel dicho Sancho de Paredes estava ausente desta dicha villa, los dichos testigos dixeron que sabían que el dicho Sancho de Paredes ha más de dos meses que no está en esta dicha villa ni es venido, e que, si venido fuese o en ella estuviese, estos testigos lo sabrían por el cargo que el dicho Sancho de Paredes tiene en la casa del señor ynfante. E luego el dicho señor alcalde, visto el dicho pedimiento e ynformaçión, dixo que dava e dio liçençia a la dicha Ysabel Cuello para que pueda hazer e haga qualquier solenidad e juramento que en este caso quisyere hazer. Testigos: Juan Velázquez e Miguel Sánchez, escrivanos públicos de la dicha villa.

E después desto que dicho es, este dicho día, mes e año susodichos, en presençia de mí, el dicho escrivano e testigos yuso escriptos, paresçió presente la dicha Ysabel Cuello e dixo que jurava a Dios, nuestro Señor, e a la señora de la cruz, en que puso su mano derecha, e a las palabras de los Santos Evangelios, como buena e católica christiana, que todas las joyas de oro e plata e perlas e piedras, brocado e sedas, e tapiçería e ropas de vestir e hornamentos e cosas de capilla e otras joyas e cosas que me fueron entregadas para thener en la cámara de la dicha reyna, nuestra señora, desde el día que su altesa me mandó dar e dio el dicho cargo, que no queda ni finca en mi poder ni de otra persona en mi nonbre ninguna cosa dello, eçebto de las cosas que su alteza me hizo merçed, e, después de su fin, sus testamentarios, e que todo lo otro, syn dethener cosa dello, lo dimos y entregamos, yo e el dicho mi marido, realmente y con efeto a las personas a quien su alteza, en su vida e después los dichos sus testamentarios, mandaron, e que la cuenta que dello se dio a los señores contadores de cuentas de sus altezas es buena, çierta, leal e verdadera, e que en ella ni en parte della no ay fraude ni engaño ni encubierta alguna a todo mi leal saber y entender, en fe de lo qual firmé aquí mi nonbre. 
Ysabel Cuello [rúbrica].

Testigos que fueron presentes a lo que dicho es de suso rogados e llamados, $/{ }^{4 v}$. Alonso de Çamora, criado de Juan de Montalvo, regidor, vezino de la dicha villa, e Pedro del Ama, vezino de Sevande, lugar de la dicha villa, e Rodrigo de Toro, e Françisco Gallego, criados de la dicha Ysabel Cuello. E yo, el dicho Sancho Rodrígues, escrivano público en la dicha villa de Arévalo a la merçed de sus altesas, fui presente a lo que es dicho de suso en vno con los dichos testigos e lo fis escribir e signé en fe de verdad e doy fe que la dicha Ysabel Cuello lo firmó de su nonbre en esta dicha escritura.

Sancho Rodrígues [signo y rúbrica].

1506, enero, 27. Cáceres.

[Juramento de Sancho de Paredes ante escribano público de que entregó todas las pertenencias de la reina Isabel y no se quedó con nada]

AGS, CMC,1EP, LEG,186, s.f.

[Arriba centro:] (Cruz).

[Al margen izquierdo:] Juramento del camarero Sancho de Paredes.

Yo, Sancho de Paredes, camarero de la reyna doña Ysabel, nuestra señora, que Santa Gloria aya, juro a Dios, nuestro Señor, e a Santa María e por la señal de la Cruz, tal como esta (Cruz), en que puse mi mano derecha, e por las palabras de los Santo Ebangelios, doquier que están escritos, como bueno e católico christiano, que todas las joyas de oro e plata e perlas e piedras, brocados e sedas e tapiçería e ropas de vestir e hornamentos e cosas de capilla e otras joyas e cosas que nos fueron entregadas para tener en la cámara de la dicha reyna, nuestra señora, desde el día que su alteza mandó dar el dicho cargo que no finca ni queda en mi poder ni de otra persona en mi nonbre ninguna cosa dello, ebçeto de las cosas que su alteza me hizo merçed e, después de su fin, sus testamentarios, eçebto doze arcas viejas e ocho reposteros traýdos e algunas caxas de madera en que truxe a mi casa algunas cosas mías, e que todo lo otro, syn detener cosa, lo dimos y entregamos realmente e con efeto a las personas a quien su alteza, en su vida e después los dichos testamentarios, nos mandaron, e que la cuenta que dello dimos a los señores contadores mayores de cuentas de sus altezas es buena, çierta, leale verdadera, e que en ella ni en parte della no ay fraude ni engaño ni encovierta alguna a todo nuestro saber e entender, e con protestaçión que sy alguna cosa yo no sopiera lo declara, so cargo del dicho juramento.

Sancho de Paredes [rúbrica]

Que fue fecho en la villa de Cáçeres, a veynte e syete días del mes de henero, año del nasçimiento de nuestro Salvador Ihesuchristo de mill e quinientos e seys años, en presençia de mi, Baltasar Manuel, escrivano público e uno de los del número en la dicha 
villa de Cáçeres e su tierra por sus altezas. Testigos que fueron presentes a todo esto que dicho es e vieron firmar su nonbre aquí al dicho Sancho de Paredes, Pedro Durán e Bartolomé González e Fernando Molina, canteros, vezinos de la dicha villa de Cáçeres. E yo, el dicho Baltasar Manuel, escrivano público susodicho, presente fui a todo lo que dicho es en uno con los dichos testigos e, por ende, de ruego e otorgamiento del dicho Sancho de Paredes esta escriptura escreví e fiz escrivir segno que ante mí pasó, e, por ende, fiz aquí este mío sygno a tal [signo] en testimonio de verdad.

Baltasar Manuel, escrivano [rúbrica].

1506, febrero, 05. Salamanca

[Carta de finiquito de la Contaduría Mayor de Cuentas en nombre de la reina Juana a Sancho de Paredes e Isabel Cuello de todas las cosas de la cámara de la reina Isabel que tuvieron a su cargo]

TPGB, Libro de fin y quito, s.f.

AGS, CMC,1EP, LEG,186, s.f.

Doña Juana, por la graçia de Dios, reyna de Castilla, de León, de Granada, de Galizia, de Sevilla, de Córdova, de Murçia, de Jahén, de los Algarves, de Algezira, de Gibraltar e de las yslas de Canaria, señora de Vizcaya e de Molina, prinçesa de Aragón e de Seçilia, archeduquesa de Abstria, duquesa de Borgoña, por quanto vos, Sancho de Paredes, camarero que fuystes de la reyna doña Ysabel, mi señora madre, que aya Santa Gloria, fuystes llamado por los mis qontadores mayores de quentas para que les diesedes cuenta e razón de todas las joyas de oro e plata e piedras e perlas e brocados e sedas e tapiçería e ornamentos e ropas de bestir e dineros e otras qualesquier cosas que vos e Ysabel Cuello, asýmismo camarera, vuestra muger, teníades y eran a vuestro cargo, de que no les avíades dado cuenta, asý de antes que la dicha reyna, mi señora madre, pasase desta presenta vida como después, e vos paresçistes ante ellos e presentastes dos çédulas fyrmadas del muy alto e muy poderoso rey don Fernando, mi señor padre, administrador e governador destos mis reynos, e firmadas en las espaldas dellas de los otros testamentarios de la dicha reyna, mi señora madre, su thenor de las quales dichas çédulas, uno en pos de otro, es esto que se sygue:

El Rey.

Sancho de Paredes e Ysabel Cuello, vuestra muger, camareros de la señora reyna doña Ysabel, mi muger, que aya Santa Gloria. Sabed que la dicha señora reyna, entre las cláusulas de su testamento dixo una cláusula, su thenor de la qual es este que se sygue: Yten, mando que para conplir e pagar las debdas e cargas e otras cosas en este mi testamento contenidas se ponga en poder del dicho Juan Velázquez, mi testamentario, todas mis ropas e joyas e cosas de oro e plata e otras cosas de mi cámara e persona, e 
lo que yo tengo en otras partes qualesquier, lo que estoviere en moneda e dineros en poder del dicho Iohan López de Leçárraga, mi testamentario, para que de allí se cunpla e pague como dicho es,

Por ende yo vos mando que luego entreguedes realmente e con hefecto al dicho Juan Velázquez o a quien su poder obyere todas las ropas e ornamentos e joyas e piedras e perlas e oro e plata e camas e tapiçería e sedas e brocados e paños e ropa blanca e todas las otras cosas de qualquier valor e calidad que sean e están en vuestro poder, que son a vuestro cargo, que en qualquier manera pertenezcan a la dicha señora reyna, que aya santa gloria, e, asýmismo entregar al dicho Juan López de Leçárraga todos los dineros e monedas de oro e plata que están en vuestro poder e es a vuestro cargo, pertenesçientes a la dicha señora reyna o a quien su poder obyere, e tomar carta de pago de los dichos Juan Velázquez e Juan López e de quien poder obyere de cada uno dellos de lo que asý les diéredes y entregáredes, con las quales e con esta mi çédula e por virtud de la sobredicha cláusula mando a los contadores mayores de cuentas e a otra qualquier persona e personas que oviere de aver e reçebir vuestras cuentas que vos lo reçiban e pasen todo en quenta syn otro recabdo alguno. Fecha en la çibdad de Toro, a treynta días del mes de setienbre ${ }^{95}$ de quinientos e çinco años. Yo, el Rey. Por mandado del rey, administrador e governador, Gaspar de Grizio. Toletanus archepiscopus. Yspalensis. Antonio de Fonseca. Juan Velázquez. Juan López.

En las espaldas de la qual dicha çédula estava escrito lo syguiente:

Yo, Gaspar de Grizio, secretario de la reyna doña Ysabel, que aya Santa Gloria, doy fe, por la presente, que al tiempo que su alteza otorgó ante mí su testamento e postrimera voluntad, dexó por sus testamentarios al señor rey don Fernando, su marido, e a los reberendísimos señores don Françisco Ximénez de Çisneros, arçobispo de Toledo, su confesor e de su consejo, e don frey Diego Deça, arçobispo de Seuilla, e a la sazón hera obispo de Palençia, confesor del dicho señor rey e de su consejo, e Antonio de Fonseca, su contador mayor, e a Juan Velázquez, contador mayor que entonçes hera de la señora prinçesa doña Juana, anvos del su consejo, e a Juan López de Leçárraga, su secretario, e les dio por el dicho su testamento su entero poder e facultad para entrar e tomar todos sus bienes muebles doquier que los pudiese hallar e los vender e gastar e distribuir para conplir e pagar las cosas en su testamento contenidas, según más largamente en el dicho su testamento se qontiene, e, asýmismo, doy fe como la cláusula que en esta çédula de su alteza de esta otra parte escrita va ynxerta es la misma de berbo ad berbun que la dicha reyna doña Ysabel por el dicho su testamento ante mí otorgó, la qual yo saqué del dicho testamento para la yncorporar e poner en esta dicha çédula. Gaspar de Grizio.

\section{El Rey.}

Sancho de Paredes, camarero de la serenísima reyna, mi muy cara e amada muger, que aya Santa Gloria. Sabed que yo e los otros testamentarios de su señora acordamos que las joyas de oro e plata e piedras e perlas e brocados e seda e tapiçería e cosas de

95 error, es diciembre de 1504 , no septiembre (en septiembre todavía no había muerto la reina Isabel). 
camas e todas las otras cosas de su cámara se bendan para conplimiento de su ánima, comoquier que por una cláusula de las del testamento de su señoría dize que se abýan de entregar todas a Juan Velázquez, la qual dicha cláusula, de berbo ad berbun, es esta que se sigue:

Yten, mando que para conplir e pagar las debdas e cargos e otras cosas en este mi testamento contenidas se ponga en poder del dicho Juan Velázquez, mi testamentario, todas mis ropas e joyas e cosas de oro e plata e ottras cosas $\mathrm{de}<\mathrm{mi}>$ cámara e persona, e lo que yo tengo en otras partes qualesquier, e lo que estoviere en moneda e dineros en poder del dicho Juan López de Leçárraga, mi testamentario, para que de allí se cunpla e pague como dicho es.

E sy todas las dichas joyas de oro e plata e piedras e perlas e otras cosas susodichas el dicho Juan Velázquez oviese de vender, avría mucha dilaçión e no se podría conplir tan presto las mandas qontenidas en su testamento, yo vos mando e doy liçençia e facultad para que vendáys todas las dichas joyas de oro e piedras e perlas e todas las otras cosas de vuestro cargo según que están tasadas en los libros de la cámara de su señora e se tasaren e retasaren agora por ante Suero de Cangas, escrivano de cámara, eçebto los ornamentos e joyas de capilla con que se sirbýa la capilla de su señoría, e los vestidos de su persona, e mando que acudáys con el dinero que montare en las dichas joyas de oro e plata e piedras e perlas e todas las otras cosas que vos tenéys a vuestro cargo, no obstante la dicha cláusula que de suso va encorporada, a Bartolomé de Çuluaga, según que paresçiere estar tasado por los dichos libros, e lo que agora se tasare e retasare, firmado del dicho Suero de Cangas, e, asýmismo, con las çédulas mías, por las quales yo libraré los maravedís que montare en las joyas que yo tomare de las que estovieren a vuestro cargo, e con las obligaçiones de las personas que han tomado fiadas qualesquier cosas de la dicha cámara, para que recabde con ellas los maravedís que en ellas montare, e mando que vos dé conosçimientos de los maravedís que montare en las dichas çédulas e obligaçiones, asý como de los otros maravedís que de vos resçibiere en dineros contados, por quanto las dichas obligaçiones e çédulas se hizieron con acuerdo mío e de los otros testamentarios e por nuestro mandado, e tomar sus cartas de conosçimientos de todos los maravedís e çédulas e obligaçiones que así le entregáredes, con las quales e con esta mi çédula mando a los contadores mayores de quentas que vos reçiban e pasen en quenta todas las joyas de oro e piedras e perlas e piedras e tapiçería e brocados e sedas e paños e otras cosas que montare en la quenta o quentas de maravedís e çédulas e obligaçiones que asý diéredes y entregáredes al dicho Bartolomé de Çuluaga, e, asýmismo, mando a los dichos contadores que con los conosçimientos quel dicho Bartolomé de Çuluaga vos diere vos descargen e den por libre e quito de todas las joyas e otras cosas que vos asý vendiéredes, no enbargante quel dicho Bartolomé de Çuluaga lo aya de vos reçibido en dineros e obligaçiones e çédulas, en manera que vos no sea fecho otro cargo alguno de los maravedís que montaron dichas joyas e otras cosas que asý vendiéredes, e mando a los dichos qontadores mayores de quentas e a sus lugarestenientes que no fagan cargo alguno al dicho Juan Velázquez de las cosas susodichas que asý vendiéredes, de quel dicho Bartolomé de 
Çuluaga vos diere sus conosçimientos, salvo solamente de las cosas que paresçiere que ha resçibido o resçibyere el dicho Juan Velázquez por conosçimientos fyrmados de su nonbre, e por vos pasar en quenta todas las cosas qontenidas en esta dicha çédula no les sea ynputado ni puesto culpa ni cargo a los dichos qontadores mayores de quentas e a sus lugarestenientes. Fecha en la çibdad de Toro, a quinze días del mes de hebrero de mill e quinientos e çinco años. Yo, el Rey. Por mandado del rey, administrador e governador, Gaspar de Grizyo.

En las espaldas de la qual dicha çédula estavan escritos los nonbres syguientes: Toletanus. Yspalensis. Antonio de Fonseca. Juan López.

E por vos, el dicho Sancho de Paredes, fue pedido a los dichos mis qontadores mayores de quentas que viesen las dichas çédulas e, asýmismo, otras çédulas e mandamientos de que adelante faze relaçión, que él tenía para su descargo, algunos dellos firmados de la dicha reyna, mi señora, y otros firmados del dicho rey, mi señor e padre, e, conforme a ellos, vos tomasen la dicha cuenta e razón, lo qual por ellos fue visto e vieron los libros de vuestro cargo de la dicha cámara e las nóminas e recabdos e escrituras que para vuestro cargo e data fueron menester, de que tomaron e quedó en los libros que ellos tenían la relaçión conplidamente, por virtud de lo qual todo que dicho es fizieron la dicha vuestra cuenta de la forma e manera que aquí será declarado en esta guisa:

[Relación de las descripciones de todos los objetos entregados, a lo largo de 272 folios]

\section{El Rey}

Contadores mayores de cuentas, sabed que Sancho de Paredes, camarero de la señora reyna mi muy cara e amada muger que aya santa gloria e Ysabel Cuello su muger, me hiçieron relaçión a mí e a los otros testamentarios de su señoría que en las cuentas que vos han dado de las cosas de sus cargos de la cámara de su señoría les alcança entre las otras cosas del cargo e la data las cosas siguientes:

Ocho onças e dos ochavas de anbar

Una almohada de rras rrayda

Una caxa larga de cuero negro forrada en grana

Dos vancos de cama de rroble tasado en un castellano

Media capilla de capus a las bueltas de las mangas chiquitas

Ciertas tiras de carmesí de las aberturas

Un arito de oro rredondo que pesó un tomín e çinco granos

Tres correas guarnesçidas

Unos pedaços de lienços de colores

Quatro harpilleras

Un cinto de terçiopelo verde con su bolsa e cordones 
Dos pares de rriendas grandes de latón

Una faxa de Florençia de una terçia

Un papagayo

Un pedaço de lienço de rruán de dos varas de bocarán e dos de lienço negro

Diez sortijas de hierro doradas e quatro puntas de terçiopelo

Tres aforros de cortinas de tafetán.

Las quales dichas cosas dis que se perdieron o las gastaron en serviçio de sus señorías de que no reçibieron recabdos o si los reçibieron los han perdido. Suplicáronme sobre ello les mandase proveer como fuese mi merced lo qual visto por mí e por los otros testamentarios de su señoría e considerando la fidelidad de los dichos Sancho de Paredes e Ysabel Cuello su muger e que como tales se haçen cargo de otras muchas cosas que por los libros no paresçe cargo contra ellos, fue acordado que devía mandar dar esta mi çédula para vosotros por la qual vos mando que reçibays e paseys en cuenta de las cosas de sus cargos de la cámara de su señoría a los dichos Sancho de Paredes e Ysabel Cuello su muger todas las cosas de suso en esta mi nómina contenidas sin les pedir otro mandamiento ni carta de pago ni otro recabdo alguno e si es nesçesario vos relievo de qualquier cargo o culpa que por ello vos sea ynputado. Fecha en Salamanca a veynte e çinco días de enero de quinientos e seys años. Yo el rey por mandado de su alteza. Juan Lópes, e en las espaldas de la dicha çédula están escrito lo siguiente: Toletanus. Juan Lopes.

Las quales dichas cosas de susodeclaradas que en esta mi carta de fin e quito van cargadas e descargadas a los dichos Sancho de Paredes e Ysabel Cuello por los dichos mis contadores mayores de cuentas fueron conprovadas e averiguadas por los libros de la cámara de la dicha reyna mi señora que tenían sus escrivanos de la cámara las quales averiguadas e conçertadas por los dichos libros son más aquello que vosotros declarastes por descargo de vuestras conçiençias que estava en vuestro poder que los dichos escrivanos no vos tenían cargado se vos cargó e descargó en la susodicha cuenta que los dichos mis contadores mayores de cuentas vos tomaron e de todo ello averiguado el cargo e descargo, paresçe que de todas las cosas que estaban a vuestro cargo y reçebistes para tener en la dicha cámara no quedó ni fincó en vuestro poder cosa alguna eçebto dies e siete marcos menos dos ochavas de plata en pasta e tres ochavas e tres tomines de oro de veynte e dos quilates que se vos alcançó en toda la dicha cuenta con lo qual por los dichos mis contadores mayores de cuentas vos fue mandado que acudiesedes con ello a Bartolomé de Çuloaga tesorero de los descargos de la dicha reyna mi señora e le fisieron cargo dellos e vos gelo aveys de haser pagado no enbargante esta mi carta de fin e quito.

Agora, por quanto vos los dichos Sancho de Paredes e Ysabel Cuello, vuestra mujer, camareros de la señora reyna doña Ysabel, mi muy cara e amada madre, que aya santa gloria, me suplicastes e pedistes por merçed que pues aviades dado e distes a los dichos 
mis contadores mayores de cuanto la dicha vuestra cuenta de las dichas joyas e otras cosas de suso declaradas que vosotros avíades devido e fueron a vuestro cargo en la dicha cámara de la dicha rreyna mi señora que en gloria sea, que a mi merçed plugiere // de vos mandar dar mi carta de fin y quito de todo ello e como la mi merçed fuese e por quanto por los dichos mis contadores de cuentas fueron vistos e averiguados todos los cargos que vos estavan fechos por los libros de Diego de Medina e Françisco de Hermosilla e Juan de Cabrera e Diego de Salinas e Diego Ramires e Suero de Cangas e por otros escrivanos que fueron de la cámara de la dicha rreyna mi señora e los libros que los dichos mis contadores mayores de cuentas tienen de tesoreros e otras personas por donde se vos hasía e podía aser qualesquier cargos e porque ellos vieron e conprovaron la dicha vuestra cuenta de todas las dichas cosas que así aviades reçibido e vos estaban cargadas e avíades fecho durante el tienpo que fuedes camarero de la dicha rreyna mi señora fasta el día que falleçió e porque de todo lo que ansí paresçió ser a vuestro cargo mostrastes los recabdos e deligençias de suso declaradas en manera que no fincó ni finca contra vos alcançe de cosa alguna dello e demás desto por vos los dichos Sancho de Paredes e Ysabel Cuello vuestra muger por ante los dichos mis contadores mayores de cuanto fue fecho juramento en forma devida de derecho que la dicha cuenta que asy les distes es buena e çierta e leal e verdadera e que en ella ni en parte alguna de ella no ay fraude ni encubierta alguna e que en vuestro poder ni de alguno de vuestro cargo cosa alguna ni parte dello eçebto de aquello de que la dicha rreyna mi señora en su vida e después el rrey mi señor padre e los otros testamentarios de su altesa vos hisieron merçed tovelo por bien. Por ende yo la dicha rreyna doña Juana por esta mi carta de fin e quito lo o e apruevo la dicha carta que así vos fue tomada por los dichos mis contadores mayores de cuentas en la manera que dicha es e la ho por buena e çierta e verdadera e doy por libres e quitos a vos los dichos Sancho de Paredes e Ysabel Cuello e a vuestros herederos e subçesores e aquel e aquellos que de vos o dellos oviere vynculo o cabsa para sienpre jamás de todas las cosas en esta dicha mi carta de fin e quito contenidas e quiero e me plaze e es mi merçed e voluntad que contra vosotros ni contra vuestros bienes ni de los dichos herederos e subçesores ni algo de vos no me quede ni finque de mi ni de los reyes mis predeçesores derecho ni abçión ni rrecurso alguno por rrasón de lo que dicho es ni de cosa alguna dello, e mando a los dichos mis contadores mayores de cuentas e a sus lugarestenientes así a los que agora son como a los que serán de aquí adelante que vos no llamen ni çiten ni fagan çitar ni llamar para que les ayades de dar otra vez la dicha cuenta de su ofiçio ni a pedimiento de nuestro procurador fiscal ni en otra manera alguna e si vos llamaren que no seays obligados a venir ni paresçer ante ellos e por ello no yncurrades en pena ni calumnia alguna e mando a los alcaldes e otras justyçias qualesquier de mi casa e corte e chançillería e de la villa de Cáçeres e de todas las otras çibdades e villas e lugares de los mis rreynos e señoríos que agora son o serán de aquí adelante que vos guarden e hagan guardar esta mi carta de fin e quito en todo e por todo segund e cuanto en ella se contiene e contra el tenor e forma della vos no vayan ni pasen ni consientan yr ni pasar en tienpo alguno ni por alguna manera so pena de la mi merçed e de diez mile 
maravedís para la mi cámara e desto vos mandé dar e di esta mi carta de fin e quito sellada e librada de los mis contadores mayores de cuentas e de sus lugartenientes dada en la çibdad de Salamanca a treynta días del mes de diziembre año del nasçimiento de nuestro Salvador Ihesu Christo de mile e quinientos e çinco años.

$[\ldots]$

Va escrito este finiquito en dosientas e setenta e dos hojas deste libro. A más esta en que se concluyó e porque desde que esta cuenta començó a tomar a vos los dichos Sancho de Paredes e Ysabel Cuello fasta que se acabó de concluyr por su mucha distançia de tiempo e la data de él se hinchó en el año de quinientos e çinco a treinta de diziembre de él. Lo çierto es que la dicha cuenta se acabó de tomar en Salamanca a çinco de hebrero de mile e quinientos e seys lo qual se hiso así porque el dicho finiquito estava ya escrito con el ditado de mí, la dicha reyna doña Juana e porque se sellase e despachase así e no se tornase a haser por la mucha escritura del dicho finiquito.

Rodericus de Qualla, liçençiatus - Rodericus Ruyz - Rodericus de Alcoçer - Castañeda chançiller. 


\section{Bibliografía}

ANDRÉs DíAz, Rosana de, El último decenio del reinado de Isabel I a través de la tesorería de Alonso de Morales (1495-1504), Universidad de Valladolid, Valladolid, 2004. Azcona, Tarsicio de, Isabel la Católica. Estudio crítico de su vida y reinado [BAC Normal 237], Biblioteca de Autores Cristianos, Madrid, ${ }^{3} 1993$.

Cañas Gálvez, Francisco de Paula, "La cámara de Juan II: vida privada, ceremonia y lujo en la corte de Castilla a mediados del siglo XV" en: GAMBrA GutiérRez, Andrés; Labrador Arroyo, Félix (coords.), Evolución y estructura de la Casa Real de Castilla, Polifemo, Madrid, 2010, vol. 1, pp. 81-195.

Cañas Gálvez, Francisco de Paula, "Las casas de Isabel y Juana de Portugal, reinas de Castilla. Organización, dinámica institucional y prosopografía (1447-1496)" en: MARtínez Millán, José; Marçal Lourenço, Maria Paula (coords.), Las relaciones discretas entre las Monarquías Hispana y Portuguesa: Las Casas de las Reinas (siglos XV-XIX), Polifemo, Madrid, 2009, vol. 1, pp. 9-231.

Cañas Gálvez, Francisco de Paula, Burocracia y Cancillería en la corte de Juan II de Castilla (1406-1454). Estudio institucional y prosopográfico, Ediciones Universidad de Salamanca, Salamanca, 2012.

Cañas Gálvez, Francisco de Paula, La Cámara Real de Juan II de Castilla. Cargos, descargos, cuentas e inventarios (1428-1454), Ergástula, Madrid, 2016.

Carpallo Bautista, Antonio, "La encuadernación del libro en la Edad Media", Avenoza, Gemma; Fernández Fernández, Laura; Soriano Robles, M. Lourdes (eds.), La producción del libro en la Edad Media. Una visión interdisciplinar, Sílex, Madrid, 2019, pp. 207-241.

Carriazo, Juan de Mata (ed.), Memorial de diversas hazañas: crónica de Enrique IV, ordenada por Mosén Diego de Valera, Espasa-Calpe, Madrid, 1941.

Domínguez Casas, Rafael, Arte y etiqueta de los Reyes Católicos. Artistas, residencias, jardines y bosques, Alpuerto, Madrid, 1993.

Domínguez CAsas, Rafael, "Las Casas de las reinas hispano-portuguesas de Juan II a los Reyes Católicos” en: Martínez Millán, José; Marçal Lourenço, Maria Paula (coord.), Las relaciones discretas entre las Monarquías Hispana y Portuguesa: Las Casas de las Reinas (siglos XV-XIX), Polifemo, Madrid, 2009, vol. 1, pp. 233-275.

Domínguez Casas, Rafael, "División de espacios hombres-mujeres en la Corte de los Reyes Católicos" en: Birriel Salcedo, Margarita María (ed.), La(s) casa(s) en la Edad Moderna, Institución Fernando el Católico, Zaragoza, 2017, pp. 155-191.

Fernández de Córdova Miralles, Álvaro, La Corte de Isabel I. Ritos y ceremonias de una reina (1474-1504), Dykinson, Madrid, 2002.

Fernández de Córdova y Miralles, Álvaro, "Sociedad cortesana y entorno regio": Medievalismo. Boletín de la Sociedad Española de Estudios Medievales 13-14 (2004) pp. 49-78. 
Fernández de Oviedo, Gonzalo, Batallas y quinquagenas, 2 vols., Real Academia de la Historia, Madrid, 1983-2000.

García Alcázar, María Francisca, "Los 'continos' reales de Castilla durante la Baja Edad Media. Estado de la cuestión”, Espacio, Tiempo y Forma. Serie III, Historia Medieval 30 (2017) pp. 335-358.

GonzÁlez Marrero, María del Cristo, La casa de Isabel la Católica. Espacios domésticos y vida cotidiana, Institución Gran Duque de Alba, Ávila, 2005.

González Marrero, María del Cristo, "Las mujeres de la Casa de Isabel la Católica" en: Martínez Millán, José; Marçal Lourenço, Maria Paula (coords.), Las relaciones discretas entre las Monarquías Hispana y Portuguesa: Las Casas de las Reinas (siglos $X V$-XIX), Polifemo, Madrid, 2009, vol. 2, pp. 841-886.

Hernández Esteve, Esteban, "La contaduría mayor de cuentas de Castilla en tiempos de los Reyes Católicos (1474-1515)" en: Doctor Antonio Goxens Duch: la imagen fiel, Universitat de Barcelona, Barcelona, 1997, pp. 95-133.

Las Siete Partidas del Sabio Rey don Alonso el nono, nueuamente Glosaas por el Licenciado Gregorio Lopez del Consejo Real de Indias de su Magestad. Impresso en Salamanca por Andrea de Portonariis, impressor de su Magestad. Año MDLV, Boletín Oficial del Estado, Madrid, 1985.

Martín Barba, José Julio, "Identificación de un libro propiedad de Isabel la Católica: el Smaragdo de la catedral de Córdoba", De medio Aevo 12 (2018) pp. 13-46.

Martín Barba, José Julio, "La fortuna del Smaragdo de Córdoba desde su creación hasta la almoneda de los bienes de Isabel I de Castilla", De medio Aevo 13 (2019) pp. 177-212.

MArtín BArBA, José Julio, “El desarrollo de la almoneda de los bienes muebles de Isabel la Católica", Historia, Instituciones, Documentos 13 (2019) pp. 249-282.

Mogollón CAno-Cortés, Pilar, "Arte y poder de las familias hidalgas cacereñas en tiempos de Fernando el Católico. El Palacio de los Golfines de Abajo" en: Bernal, Antonio Miguel (ed.), Fernando el Católico, rey, Marcial Pons, Madrid, 2016, pp. 95-119.

Mogollón CANO-Cortés, Pilar, "Símbolos e imágenes de la fachada de la casa del camarero Sancho de Paredes en Cáceres”, Hispanic Research Journal 18/5 (2017), pp. 373-390.

Ortí Belmonte, Miguel Ángel, “Cáceres bajo la Reina Católica y su camarero Sancho Paredes Golfin”, Revista de Estudios Extremeños 10 (1954), pp. 193-328.

Panizo Santos, Ignacio, Análisis institucional, gestión administrativa y tramitación documental de la cámara de Isabel I de Castilla [tesis doctoral]: https://academica-e. unavarra.es/xmlui/handle/2454/32552

Pelaz Flores, Diana, La Casa de la Reina en la Corona de Castilla (1418-1496), Universidad de Valladolid, Valladolid, 2017.

Ruiz García, Elisa, Los libros de Isabel la Católica: arqueología de un patrimonio escrito, Instituto de Historia del Libro y de la Lectura, Madrid, 2004. 
Solana Villamor, Ma Concepción, "Cargos de la Casa y Corte de los Reyes Católicos. Los modestos colaboradores de los Reyes Católicos" en: Cuadernos de la Cátedra de Paleografía y Diplomática de Valladolid III, Valladolid, 1962.

Torre y del Cerro, Antonio de la, Cuentas de Gonzalo de Baeza, tesorero de Isabel la Católica. Tomo II: 1492-1504, Consejo Superior de Investigaciones Científicas, Patronato Marcelino Menéndez Pelayo, Madrid, 1956.

Torre y del Cerro, Antonio de la, La casa de Isabel la Católica, Consejo Superior de Investigaciones Científicas, Patronato Marcelino Menéndez Pelayo, Madrid, 1954.

Torre y del Cerro, Antonio de la, Testamentaría de Isabel la Católica, Barcelona, 1974. 